\title{
$\beta$-Catenin Is Required for Endothelial Cyp1b1 Regulation Influencing Metabolic Barrier Function
}

\author{
Nicole Ziegler, ${ }^{1}$ Khader Awwad, ${ }^{2}$ Beate Fisslthaler, ${ }^{2,3}$ Marco Reis, ${ }^{4}$ Kavi Devraj, ${ }^{1}{ }^{\oplus}$ Monica Corada, ${ }^{5}$ \\ - $S$ Simone Paolo Minardi, ${ }^{-}$Elisabetta Dejana, ${ }^{5,6,7}$ Karl H. Plate, ${ }^{1,3}$ - Ingrid Fleming, ${ }^{2,3}$ and ${ }^{\circledR S t e f a n ~ L i e b n e r ~}{ }^{1,3}$ \\ ${ }^{1}$ Institute of Neurology (Edinger-Institute), Goethe-University Frankfurt Medical School, 60528 Frankfurt, Germany, ${ }^{2}$ Institute for Vascular Signaling, \\ Goethe University, 60596 Frankfurt, Germany, ${ }^{3}$ German Center for Cardiovascular Research, Partner Site Rhine-Main, 60528 Frankfurt, Germany, ${ }^{4}$ Roche \\ Innovation Center Penzberg, Pharma Research and Early Development, Oncology, Roche Diagnostics GmbH, 82377 Penzberg, Germany, ${ }^{5}$ FIRC Institute of \\ Molecular Oncology, 20139 Milan, Italy, ${ }^{6}$ Department of Immunology, Genetic and Pathology, University of Uppsala, 75105 Uppsala, Sweden, and \\ ${ }^{7}$ Dipartimento di Bioscienze, University of Milan, 20133 Milan, Italy
}

The canonical Wnt/ $\beta$-catenin signaling pathway is crucial for blood-brain barrier (BBB) formation in brain endothelial cells. Although glucose transporter 1, claudin-3, and plasmalemma vesicular-associated protein have been identified as Wnt/ $\beta$-catenin targets in brain endothelial cells, further downstream targets relevant to BBB formation and function are incompletely explored. By Affymetrix expression analysis, we show that the cytochrome P450 enzyme Cyp1b1 was significantly decreased in $\beta$-catenin-deficient mouse endothelial cells, whereas its close homolog Cyplal was upregulated in an aryl hydrocarbon receptor-dependent manner, hence indicating that $\beta$-catenin is indispensable for Cyp1b1 but not for Cyplal expression. Functionally, Cyp1b1 could generate retinoic acid from retinol leading to cell-autonomous induction of the barrier-related ATP-binding cassette transporter P-glycoprotein. Cyp1b1 could also generate 20-hydroxyeicosatetraenoic acid from arachidonic acid, decreasing endothelial barrier function in vitro. In mice in vivo pharmacological inhibition of Cyp $1 \mathrm{~b} 1$ increased BBB permeability for small molecular tracers, and $C y p 1 b 1$ was downregulated in glioma vessels in which $\mathrm{BBB}$ function is lost. Hence, we propose $C y p 1 b 1$ as a target of $\beta$-catenin indirectly influencing BBB properties via its metabolic activity, and as a potential target for modulating barrier function in endothelial cells.

Key words: $\beta$-catenin; Cyp1b1; cytochrome P450; glioma; transcriptional regulation; Wnt signaling

Significance Statement

$\mathrm{Wnt} / \beta$-catenin signaling is crucial for blood-brain barrier (BBB) development and maintenance; however, its role in regulating metabolic characteristics of endothelial cells is unclear. We provide evidence that $\beta$-catenin influences endothelial metabolism by transcriptionally regulating the cytochrome P450 enzyme Cyp1b1. Furthermore, expression of its close homolog Cyplal was inhibited by $\beta$-catenin. Functionally, Cyp1b1 generated retinoic acid as well as 20 hydroxyeicosatetraenoic acid that regulated $\mathrm{P}$-glycoprotein and junction proteins, respectively, thereby modulating $\mathrm{BBB}$ properties. Inhibition of Cyplb1 in vivo increased BBB permeability being in line with its downregulation in glioma endothelia, potentially implicating $C y p 1 b 1$ in other brain pathologies. In conclusion, Wnt/ $\beta$-catenin signaling regulates endothelial metabolic barrier function through $C y p 1 b 1$ transcription.

\section{Introduction}

Endothelial cells (ECs) establishing the blood-brain barrier (BBB) in brain capillaries are specialized to tightly control the exchange of substances from the blood to the brain and vice versa,

\footnotetext{
Received Jan. 14, 2016; revised June 17, 2016; accepted June 27, 2016.

Author contributions: K.H.P. and S.L. designed research; N.Z., K.A., B.F., M.R., K.D., and M.C. performed research;

S.M., E.D., and I.F. contributed unpublished reagents/analytic tools; N.Z., K.D., M.C., S.M., and S.L. analyzed data; N.Z. and S.L. wrote the paper.

The study has been supported by the Deutsche Forschungsgemeinschaft SFB/TR23 Vascular Differentiation and Remodeling B7 to S.L. and A6 to I.F., the LOEWE Initiative Hessen Onkogene Signaltransduktion Frankfurt III L $4 \triangle 518 / 55.004,2009$ to K.H.P. and S.L., the Excellence Cluster Cardio-Pulmonary System to I.F., K.H.P., and S.L., and European Union Health FP7 JUSTBRAIN to E.D., K.H.P., and S.L. We thank Ann-Christin Hau for discussion and
}

ensuring homeostasis and proper brain function (Risau and Wolburg, 1990). In this context, ECs of the BBB express numerous specialized transporters, such as the solute carrier glucose transporter-1 (Glut-1), $\omega 3$-fatty acid transporter major facilita-

excellent support in ChIP experiments and data analysis; Dr. Cathrin J. Czupalla for providing RNA samples of primary mouse brain endothelial cells; and Sonja Thom and Kathleen Sommer for supporting the in vivo experiments.

The authors declare no competing financial interests.

Correspondence should be addressed to Dr. Stefan Liebner, Institute of Neurology, Goethe University Medical School, Heinrich-Hoffmann-Strasse 7, 60528 Frankfurt, Germany. E-mail: stefan.liebner@kgu.de. DOI:10.1523/JNEUROSCI.0148-16.2016

Copyright $\odot 2016$ the authors $\quad 0270-6474 / 16 / 368921-15 \$ 15.00 / 0$ 
tor superfamily domain containing 2a (Mfsd2a), and ATPbinding cassette transporters including P-glycoprotein (Pgp) (Dermietzel et al., 1992; Schinkel et al., 1994; Ben-Zvi et al., 2014). Furthermore, metabolic enzymes modulate BBB characteristics in brain ECs by influencing cellular levels of various signaling molecules, which in turn can have a considerable impact on cell function. For example, the retinol metabolite retinoic acid (RA) as well as polyunsaturated fatty acids could be shown to support barrier integrity and function, respectively (Pifferi et al., 2007; Mizee et al., 2014). The best characterized pathway controlling $\mathrm{BBB}$ development is the canonical $\mathrm{Wnt} / \beta$-catenin pathway, leading to transcriptional activity of $\beta$-catenin via the binding to transcription factors of the lymphoid enhancer factor (Lef)/Tcell factor family. Instead, the noncanonical planar cell polarity (PCP) and the $\mathrm{Wnt} / \mathrm{Ca}^{2+}$ pathways are $\beta$-catenin-independent and have been shown to modulate vascular remodeling and polarization but are not considered as master regulators of barriergenesis (Reis and Liebner, 2013; Artus et al., 2014). In brain ECs, canonical $\mathrm{Wnt} / \beta$-catenin signaling mediates the expression of BBB-relevant target genes including claudin-3 (Cldn3) and Glut-1, while suppressing the permeability-related gene plasmalemma vesicular-associated protein (Plvap/Meca-32) (Liebner et al., 2008; Stenman et al., 2008; Daneman et al., 2009). It has recently been shown that adult deletion of endothelial $\beta$-catenin leads to seizures and a lethal phenotype due to BBB deficits (Tran et al., 2016). To identify novel BBB-related genes downstream of Wnt/ $\beta$-catenin signaling, we performed Affymetrix transcriptome analysis of $\beta$-catenin knock-out (KO) ECs compared with wild-type (WT), revealing the downregulation of the metabolic enzyme Cyp1b1 in $\beta$-catenin KO ECs.

Cytochrome P450 (CYP) enzymes are essential mediators of a wide range of metabolic processes, modulating various signaling cascades and cellular behavior. In addition to their essential role in detoxification of xenobiotics, CYPs are equally important for the metabolism of endogenous substrates such as fatty acids, hormones, steroids, and vitamins (Nebert and Dalton, 2006). Consequently, dysregulation or mutations in CYP genes are potentially associated with an increasing risk of carcinogenesis as well as of pathologies including cardiovascular diseases and neurodegenerative disorders (Dutheil et al., 2010; Fleming, 2014). Variants belonging to the CYP1 family, specifically Cyp1a1 and Cyp1b1, are transcriptionally regulated by the ligand-dependent transcription factor aryl hydrocarbon receptor (Ahr) (Tukey and Nebert, 1984; Savas and Jefcoate, 1994). Upon activation, Ahr is released from HSP90 and translocates to the nucleus, where it interacts with Ahr nuclear translocator and induces target gene transcription by binding to xenobiotic-responsive elements (Zhang et al., 1998). Cyp1b1 appears to be the main CYP isoform present in human brain microvessels (Dauchy et al., 2008), consistent with its general metabolic properties suggesting a pivotal role of Cyp1b1 for BBB function.

The aim of the present study was to elucidate the endothelialspecific transcriptional regulation of Cyp $1 \mathrm{~b} 1$ by the canonical $\mathrm{Wnt} / \beta$-catenin pathway and the role of Cyp $1 \mathrm{~b} 1$ for BBB function in ECs.

\section{Materials and Methods}

Cells. $\beta$-Catenin WT (female) and $\beta$-catenin-deficient KO (female) endothelioma cells as well as VE-cadherin (Cdh5) WT (male) and KO $\left(\mathrm{Cdh} 5^{-1-}\right.$, male) endothelioma cell lines were generated as previously described (Carmeliet et al., 1999; Lampugnani et al., 2002; Cattelino et al., 2003). Endothelioma cells were cultivated on $0.1 \%$ gelatin-coated cell culture dishes in MCDB-131-based growth medium containing 15\% FCS, 2 mM L-glutamine, 1\% penicillin-streptomycin, 1\% MEM nonessential amino acids, $5 \mathrm{~mm}$ heparin, $1 \mathrm{~mm}$ sodium pyruvate, $2.5 \mathrm{~mm}$ EC growth supplement.

Affymetrix transcriptome analysis. $\beta$-Catenin WT and $\beta$-catenin KO ECs were used for transcriptome analysis (Cattelino et al., 2003). Synthesis of biotinylated cRNA targets, hybridization to Affymetrix GeneChip arrays MG_U74Av2, Bv2, and Cv2, staining and scanning were performed in accordance with the Affymetrix standard protocols, starting from $15 \mu \mathrm{g}$ of total RNA. Two copies of the GeneChips were hybridized with each cRNA sample. Microarray data were analyzed using Partek Genomics Suite software version 6.6, using RMA algorithm for summarization and normalization. $\beta$-Catenin WT and $\beta$-catenin KO conditions were compared to identify differentially expressed genes (DEGs); setting fold change (FC) $>3$ and $p<0.05$ as cutoff values, 305 transcripts were selected as differentially expressed and used for downstream analyses.

Differential expression of key transcripts is shown in a heatmap representation. Gene Ontology (GO) enrichment analysis of identified DEGs was performed using Partek Genomics Suite, whereas visualization of most relevant GO classes was performed using GOPlot library (R, Bioconductor) (Walter et al., 2015).

EC stimulation and shear stress experiments. For shear stress experiments, cells were cultured under static conditions or exposed to shear stress $\left(12\right.$ dynes $\left./ \mathrm{cm}^{2}\right)$ in a cone-plate viscosimeter for $24 \mathrm{~h}$ in serumreduced EC growth medium (Fleming et al., 2005). For stimulation, treatments were started $3 \mathrm{~h}$ after cell seeding. Stimulation conditions were as follows: $25 \mathrm{~nm}$ 2,3,7,8-tetrachlorodibenzo- $p$-dioxin solution (TCDD, Sigma-Aldrich) for $7 \mathrm{~h}$. For combination treatment of TCDD and $\mathrm{CH}-223191$ (Sigma-Aldrich): pretreatment with $10 \mu \mathrm{M} \mathrm{CH}-223191$ for $1 \mathrm{~h}$, stimulation with $25 \mathrm{~nm}$ TCDD for $7 \mathrm{~h} ; 5 \mu \mathrm{m}$ all-trans RA (atRA, Sigma-Aldrich) for $48 \mathrm{~h} ; 5 \mu \mathrm{M}$ retinol (Sigma-Aldrich) for $72 \mathrm{~h}$, whereby stimulation medium was changed every $24 \mathrm{~h} ; 10,50$, or 100 nм 20hydroxyeicosatetraenoic acid (20-HETE) (Cayman Chemical) for $24 \mathrm{~h}$. Inhibition of the noncanonical Wnt pathway was performed by $1 \mu \mathrm{M}$ cyclosporin A (Sigma-Aldrich) or $20 \mu \mathrm{M}$ SP600125 (Biozol) for $1 \mathrm{~h}$.

Retroviral and lentiviral transduction. For retroviral infection of $\beta$-catenin KO ECs with full-length murine $\beta$-catenin or Lef $\Delta \mathrm{N}-\beta \mathrm{CTA}$, amphotropic Phoenix packaging cells were transfected with expression or empty vector by standard calcium phosphate transfection procedure. Virus-containing supernatants were collected and added to the target cells being selected by puromycin treatment $(2 \mu \mathrm{g} / \mathrm{ml})$. Lentiviral infection of $\beta$-catenin KO ECs with human Cyp1b1 or control vector expressing $\beta$-galactosidase was achieved using the ViraPower Lentiviral Expression System, including the pLenti6/V5-DEST Gateway Vector Kit (Invitrogen) following the manufacturer's instructions. Target cells were transduced using a multiplicity of infection 5 . Cells were selected by blasticidin treatment $(6 \mu \mathrm{g} / \mathrm{ml})$.

Western blot analysis. Total cell lysates were harvested in Laemmli buffer. Cytoplasmic proteins were solubilized in $10 \mathrm{~mm}$ HEPES, $10 \mathrm{~mm}$ $\mathrm{KCl}, 0.1 \mathrm{~mm}$ EDTA, $0.1 \mathrm{~mm}$ EGTA, 2 mм DTT and protease inhibitors, nuclear fraction in $10 \mathrm{~mm}$ HEPES, $10 \mathrm{~mm} \mathrm{KCl}, 0.1 \mathrm{~mm}$ EDTA, $0.1 \mathrm{~mm}$ EGTA, 2 mм DTT, $400 \mathrm{~mm} \mathrm{NaCl}$, 1\% IGEPAL, and protease inhibitors. SDS-PAGE and transfer were performed by standard submerged method followed by Western blotting. Primary antibodies were as follows: rabbit anti-CYP1B1 (Abcam); goat anti-Ahr (Santa Cruz Biotechnology); mouse anti- $\beta$-catenin (BD Biosciences); goat anti-VE-cadherin (Santa Cruz Biotechnology); rabbit anti-ZO-1 (Invitrogen); rabbit antioccludin (Invitrogen); rabbit anti-JNK (Santa Cruz Biotechnology); mouse anti-pJNK (Santa Cruz Biotechnology); rabbit anti-NFAT1 (Cell Signaling Technology); rabbit anti-caveolin (BD Biosciences). Blots were visualized on $\mathrm{x}$-ray films (Super RX, FujiFilm) or using an Odyssey FC digital imaging system (LI-COR Biosciences) and quantitation was performed using ImageJ Software (National Institutes of Health) or Image Studio software (version 2.1.10), respectively. Protein levels were normalized to $\alpha$-tubulin (Sigma-Aldrich) or LaminB1 (Abcam).

$q R T-P C R$. qRT-PCR was performed using the Absolute qPCR SYBR Green Fluorescein Mix (Thermo Scientific) according to the manufacturer's protocol. Reference genes were RNA polymerase II (MGI: 98086) and G6pdx (MGI: 105979). Expression data were analyzed and significance was 
calculated with GraphPad Prism 5.0 software. Primer sequences used for cDNA amplification by qRT-PCR were as follows: 5'-GATGCCAAA GGGCAGCTTATTC- $3^{\prime}$ and $5^{\prime}$-CCACCTCCAGCGACTGTGTTT-3' for Ahr, 5'-ACCTCGCTGGTGAAGAGTCCA-3' and 5'-TCCTGAGAG CATCTGGGAACA-3' for angiopoietin-2 (Ang2), 5'-GCCGACCTC AAGTGCAAACTC-3' and 5'-GGCTGGTGCAAAGACATAGCC-3' for Axin2, 5' ${ }^{\prime}$ TGTCCTCCGTTACCTGCCTAA-3' and 5' ${ }^{\prime}$-TTCTCGTC CAGCTTCCTGTCC-3' for Cypla1, 5'-GATGTGCCTGCCACTAT TACGG-3' and 5'-CCCACAACCTGGTCCAACTCA-3' for Cyp1b1, 5'GTGAATGGCAAGCGATCATACC- $3^{\prime}$ and $5^{\prime}$-TGCCTGAAGTCATC CACACTCA-3' for occluding, 5'-GCTATCACGGCCAACATCTCC-3' and $5^{\prime}$-TGTCCAACACTGAATGCTCCAA-3' for Pgp, and 5'-TGCA GAAGTGCTTTGAAGTGG-3' and $5^{\prime}$-AAGGTTTCCTGGTGGGCT TTC-3' for Rar $\beta$. Primer sequences for human Cyplb1 were as follows: 5'-AGTGGCTGCTCCTCCTCTTCA-3' and AAGGAAGGCCAGGAC ATAGGG-3'.

Chromatin immunoprecipitation (ChIP). ECs were cultivated for $24 \mathrm{~h}$ and treated with 20 nм leptomycin B (Sigma-Aldrich) for $1 \mathrm{~h}$ before lysis. Experiments were performed, and resulting data were calculated as previously described (Agoston et al., 2014) with the following modifications: cells were fixed with $2 \%$ PFA for $10 \mathrm{~min}$ at room temperature. Nuclear pellets were resuspended in lysis buffer containing $50 \mathrm{~mm}$ Tris- $\mathrm{HCl}, 10 \mathrm{~mm}$ EDTA, 2\% SDS, $1 \mathrm{~mm}$ PMSF, and protease inhibitors. Chromatin was sheared for 45 cycles (30 s on, $60 \mathrm{~s}$ off), and $200 \mu \mathrm{g}$ of chromatin was used for each ChIP experiment. Antibodies for chromatin precipitation were as follows: rabbit anti-trimethylhistone H3 (Lys4), rabbit anti-trimethylhistone H3 (Lys27) (both Cell Signaling Technology). Primer sequences used for amplification of DNA by qRT-PCR were as follows: $5^{\prime}$-CCAGGCTCTTCTCACGCAACT- $3^{\prime}$ and $5^{\prime}$-ATCCACGCGAGACAGCAGGA-3' for Cypla1, $5^{\prime}$-CTTAGGCACCGAGCCAGGAAA-3' and 5'-GCTTTGTGTGCAGAAGGATGG-3' for Cyp1b1. Enrichment of precipitated DNA was calculated relative to input. In silico analysis of the respective promoter region to predict transcription factor binding sites was performed using Genomatix Software Suite.

Pgp activity assay. ECs were stimulated with $5 \mu \mathrm{M}$ retinol all-trans (Sigma-Aldrich) for $72 \mathrm{~h}$ and incubated with $10 \mu \mathrm{M}$ rhodamine-123 (Sigma-Aldrich) in endothelial growth medium for $1 \mathrm{~h}$ at $37^{\circ} \mathrm{C}$. Cells were lysed by adding 1\% Triton X-100 (Sigma-Aldrich). Fluorescence was determined with $505 \mathrm{~nm} / 535 \mathrm{~nm}$ excitation/emission wavelength. Experiments were performed in triplicates per condition.

Cord formation assay. Cells were incubated on Matrigel (BD Biosciences) for $18 \mathrm{~h}$ and fixed with $4 \%$ PFA. For Cyp $1 \mathrm{~b} 1$ inhibition, treatment

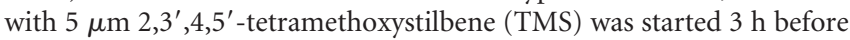
cells were seeded on Matrigel. Stimulation was maintained for $18 \mathrm{~h}$. Pictures were taken with an Olympus IX70 microscope equipped with a Hoffmann modulation contrast and a digital camera (XM10, Olympus). Objective lens was as follows: $4 \times$, Plan-Apochromat, Olympus. Experiments were performed in duplicates per condition; 4 pictures were taken per well. Number of branch points per picture was determined using ImageJ software (National Institutes of Health).

LC-MS/MS lipid profiles. ECs were stimulated with $5 \mu \mathrm{M}$ TMS (Cayman Chemical) for $3 \mathrm{~h}$ and with $10 \mu \mathrm{M}$ arachidonic acid (AA), eicosapentaenoic acid (EPA), and docosahexaenoic acid (DHA) for $24 \mathrm{~h}$. Cell supernatants were collected, spiked with deuterated internal standard, and applied to Variant Bond Elut Certify II columns preconditioned with methanol and $0.1 \mathrm{~m}$ sodium acetate buffer, $\mathrm{pH} 7$ containing $5 \%$ methanol. Samples were washed twice with $50 \%$ methanol and eluted with hexane/ethyl acetate $(75: 25, \mathrm{v} / \mathrm{v})$ containing $1 \%$ acetic acid. After evaporation of the ethyl acetate, residues were reconstituted with methanol/ water $(1: 1, \mathrm{v} / \mathrm{v})$. Eicosanoid profiles were determined with a Sciex API4000 mass spectrometer operating in multiple reaction monitoring mode as previously described (Michaelis and Fleming, 2006; Frömel et al., 2012). All of fatty acid epoxides, diols, and deuterated analogs were from Cayman Chemical.

Immunofluorescence (IF) and immunohistochemical stainings. IF stainings on cultured ECs were performed on methanol- or PFA-fixed ECs. Primary antibodies were as follows: mouse anti-Pgp (Calbiochem); mouse anticlaudin-5 (Invitrogen); rabbit anti-ZO-1 (Invitrogen); mouse anti-occludin (Invitrogen); rabbit anti-caveolin (BD Biosciences); rabbit anti-collagen IV
(ColIV) (AbD Serotec); goat anti-Podxl (R\&D Systems). As secondary antibody, the appropriate AlexaFluor-488 or AlexaFluor-568 conjugates (Invitrogen) were used. IF stainings for ColIV and Podxl were performed on $40-\mu \mathrm{m}$-thick sections of paraffin-fixed brains. Nuclei were stained with DAPI. Images were taken with a C1si confocal microscope or a Nikon $80 \mathrm{i}$ wide-field fluorescent microscope (Nikon). Objective: $40 \times$, oil, Fluor, 1.3 NA (Nikon). Images were processed and analyzed with NIS Elements AR Imaging Software (Nikon). H\&E staining was performed on $40-\mu \mathrm{m}$-thick brain sections according to standard procedures. Images were taken with an BX50 Live Microscope (Olympus). Objective: $2 \times$, Apo, 0.08 NA.

Immunoprecipitation. Proteins were solubilized in $10 \mathrm{~mm}$ HEPES, 10 mм KCl, 0.1 mм EDTA, 0.1 mм EGTA, 2 mм DTT, 400 mм NaCl, 1\% IGEPAL plus protease inhibitor mixture. Preclearing was performed with protein G-agarose beads (Roche) for $30 \mathrm{~min}$ at $4^{\circ} \mathrm{C}$ in an orbital shaker. Proteins were bound by adding $2 \mu \mathrm{g}$ of the specific antibody or IgG negative control, incubating for $2 \mathrm{~h}$ at $4^{\circ} \mathrm{C}$ and incubation overnight at $4^{\circ} \mathrm{C}$ in an orbital shaker together with Protein G-agarose beads. Beads were pelleted and resuspended in Laemmli buffer. Lysates were analyzed by SDS-PAGE and subsequent Western blot analysis.

Impedance measurement. Transendothelial electrical resistance (TEER) and capacitance ( $\mathrm{Ccl}$ ) measurements were performed with primary mouse brain microvascular ECs (pMBMECs; $10^{5} \mathrm{cells} / \mathrm{cm}^{2}$ ) seeded on 24 well filter inserts (PET ThinCerts $1.0 \mu \mathrm{m}$ pore size, $2 \times 10^{6}$ pore density, Greiner Bio One) in a cellZscope device (nanoAnalytics). Cells were stimulated with $10 \mathrm{~nm}$ 20-HETE. Analysis of TEER and Ccl data was monitored and recorded until values reached a plateau phase $( \pm 72 \mathrm{~h})$. Experiments were performed in quadruplicates per condition. Data were monitored and analyzed in the provided cellZscope software (version 1.5.3) (for further information, see also Paolinelli et al., 2013).

Permeability analysis. Fluorescently labeled tracers $0.45 \mathrm{kDa}$ Lucifer yellow (LY), 3 kDa Texas Red Dextran (TXR $3 \mathrm{kDa}$ ), $20 \mathrm{kDa}$ tetramethylrhodamine isothiocyanate dextran (TMR $20 \mathrm{kDa}$ ), and $70 \mathrm{kDa}$ fluorescein isothiocyanate dextran (FITC $70 \mathrm{kDa}$ ) in a final concentration of 10 or $5 \mu \mathrm{M}$ for FITC $70 \mathrm{kDa}$ were added to the top chamber of the filter inserts. Samples were taken from the bottom chamber after 1, 2, and $3 \mathrm{~h}$ of incubation at $37^{\circ} \mathrm{C}$. Fluorescence was analyzed using the following order of excitation/emission (in nm): TXR 595/625, TMR 550/580, FITC $490 / 520$, and LY $425 / 525$. Permeability flux was calculated as a ratio of bottom to top chamber fluorescence $(r=\mathrm{B} / \mathrm{T})$.

In vivo tracer experiments. Fourteen- to 15 -week-old C57BL/6/JRJ WT mice (Janvier Labs) were injected subcutaneously with TMS $(300 \mu \mathrm{g} / \mathrm{kg})$ or solvent control on 4 consecutive days. Three hours after the last injection, mice were anesthetized and a mixture (1:1) of $2 \mathrm{mM}$ TMR $3 \mathrm{kDa}$ dextran and $5 \mathrm{~mm}$ fluorescein-5-thiosemicarbazide (FTSC) $0.4 \mathrm{kDa}$ (both Thermo Fisher Scientific) was injected into the tail vain $(100 \mu \mathrm{l} /$ mouse) and allowed to circulate for $5 \mathrm{~min}$. After blood collection, mice were perfused with PBS. Brain and kidney were homogenized in PBS at $4^{\circ} \mathrm{C}$. Samples were centrifuged, and fluorescence of the supernatants was measured at excitation/emission wavelength of 555/585 nm for TMR dextran and 490/520 for FTSC. Raw fluorescence units (RFUs) were normalized to serum RFUs. Kidneys served as positive control for tracer injection. Animal experiments were performed with permission of the Regierungspräsidium Darmstadt (approval no. F94/18).

Tumor experiments. Intracranial tumor transplantations were performed as previously described (Reis et al., 2012).

Briefly, female, athymic NMRI-NUDE mice (strain: RjOrl:NMRIFoxn ${ }^{\nu} /$ Foxn $1^{\nu}$, Janvier Labs) were anesthetized, and $1 \times 10^{5}$ living cells in $2 \mu \mathrm{l}$ PBS was injected into the striatum at the position $3.5 \mathrm{~mm}$ dorsoventral, relative to the dura mater at the coordinates relative to bregma: $0.5 \mathrm{~mm}$ (anteroposterior), $2 \mathrm{~mm}$ (mediolateral). Subsequently, mice were killed all at once when showing glioma-specific symptoms.

Animal experiments were performed with permission of the Regierungspräsidium Darmstadt (approval no. F94/10) and in accordance with the German Legislation on the Protections of Animals and the Guide for the Care and Use of Laboratory Animals.

Statistical analysis. Results are shown as mean \pm SEM. Statistical significance was evaluated by two-tailed, unpaired Student's $t$ test (Prism version 5.0a; GraphPad Software). $p$ values $<0.05$ were considered significant. 
A

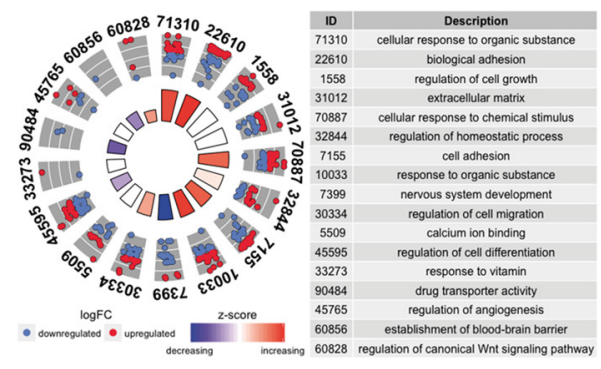

C

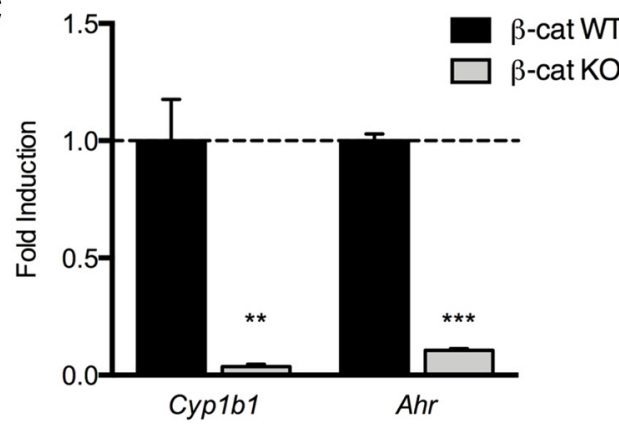

B

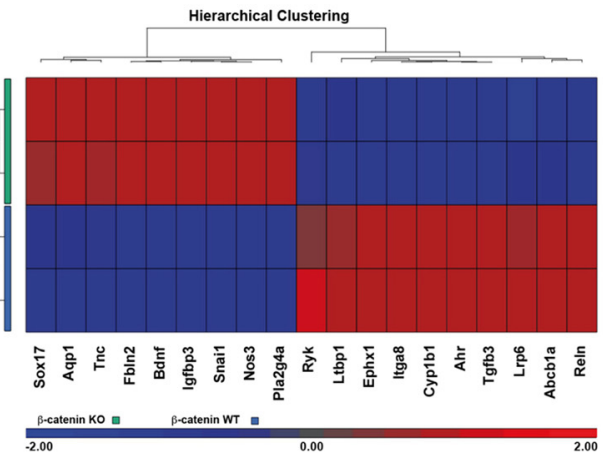

D
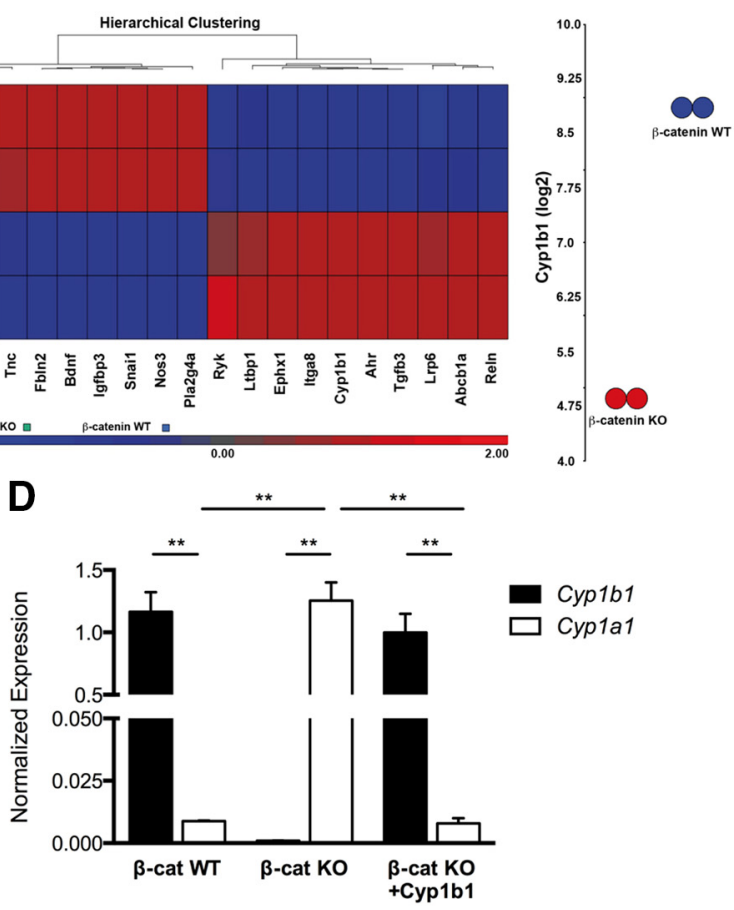

Figure 1. $\beta$-Catenin induces Cyp1b1, but not Cyp1a1 expression. $A, G 0$ enrichment analysis of identified DEGs from Affymetrix transcriptome analysis of $\beta$-catenin WT and $\beta$-catenin KO ECs. GOCirle plot for BBB-relevant G0 terms, representing upregulated or downregulated genes in $\beta$-catenin KO cells. $B$, Heatmap of selected genes from the Affymetrix transcriptome analysis of $\beta$-catenin WT and $\beta$-catenin KO ECs. Dot-plot represents Cyp 1 b1 downregulation in $\beta$-catenin KO ECs by 31-fold. C, qRT-PCR for Cyp1b1 and Ahr in $\beta$-catenin KO relative to $\beta$-catenin WT ECs (dashed line, $n=4$ ). D, qRT-PCR for mouse or human Cyp1b1 and mouse Cyp1a1 in $\beta$-catenin WT, $\beta$-catenin K0, and $\beta$-catenin K0 ECs reinfected with human Cyp1b1 $(n=3) .{ }^{* *} p<0.01 .{ }^{* * *} p<0.001$.

\section{Results}

Cyp1b1 levels were decreased in $\beta$-catenin KO ECs

To identify novel, barrier-relevant genes that are transcriptionally regulated by $\beta$-catenin, we performed Affymetrix transcriptome analysis comparing $\beta$-catenin WT and KO ECs (Cattelino et al., 2003). Gene Ontology (GO) analysis of differentially expressed genes (DEGs) revealed that several GO terms relevant for BBB induction and function are enriched upon $\beta$-catenin deletion. Specifically, genes clustering in the GO terms for cellular response to organic substances, biological adhesion, and regulation of canonical Wnt signaling pathway were significantly upregulated in $\beta$-catenin-deficient ECs, whereas genes clustering in the GO terms for nervous system development, regulation of cell differentiation, and drug transporter activity were significantly downregulated (Fig. 1A).

The cytochrome P450 (CYP) enzyme Cyp1b1 was one of the most prominent DEGs being significantly downregulated in $\beta$-catenin KO ECs at the mRNA level ( $\sim 31 \mathrm{FC}$; Fig. $1 B, C)$. Equally, Ahr transcription was decreased (Fig. $1 B, C$ ).

As Cyp1b1 and Cyp1a1 demonstrate similar substrate specificity as well as metabolic features, several publications have proposed a common mechanism of transcriptional regulation for the two enzymes (Conway et al., 2009; Procházková et al., 2011).

\section{Cyp1a1 and Cyp1b1 were antagonistically regulated by} $\beta$-catenin in ECs

Following this idea, we investigated endothelial Cyp1b1 and Cypla1 expression in the context of $\mathrm{Wnt} / \beta$-catenin signaling. qRT-PCR analyses revealed that $\beta$-catenin WT ECs expressed high levels of $C y p 1 b 1$, whereas $C y p 1 a 1$ was almost undetectable. In $\beta$-catenin $\mathrm{KO}$ cells, Cyplal transcription was significantly increased compared with WTs. Furthermore, reexpression of
Cyp1b1 in $\beta$-catenin KO ECs abrogated the increase in Cypla1 transcription (Fig. 1D). To assess whether activation of the canonical Wnt pathway could be the driving force for Cyp1b1 induction we stimulated pMBMECs with Wnt3a conditioned medium (Wnt3aCM). Pathway activation was verified by mRNA upregulation of the Wnt target gene Axin2. Cyp1b1 as well as Ahr transcription were increased, whereas Cyplal expression was not altered (Fig. 2A). To understand whether these effects were directly mediated by $\beta$-catenin transcriptional activity, $\beta$-catenin KO ECs were infected with a fusion protein of Lef1 and the transactivation domain of $\beta$-catenin (Lef $\Delta \mathrm{N}-\beta \mathrm{CTA}$ ), conferring dominant-active transcriptional activity of Lef1- $\beta$-catenin without exerting its membrane function (Vleminckx et al., 1999). Lef $\Delta$ N- $\beta$ CTA significantly upregulated Axin 2 as well as Cyp $1 b 1$ expression, whereas Cypla1 and $A h r$ transcription was decreased compared with control (Fig. 2B). These data were supported by ChIP experiments, revealing a decrease in trimethylated histone $\mathrm{H} 3$ at lysine-4 $(\mathrm{H} 3 \mathrm{~K} 4 \mathrm{Me} 3)$ and increased trimethylated histone $\mathrm{H} 3$ at lysine $27(\mathrm{H} 3 \mathrm{~K} 27 \mathrm{Me} 3)$ in the promoter region of Cyp1b1 in $\beta$-catenin KO ECs compared with WT, chromatin marks generally associated with active or repressed transcription, respectively (Fig. 2C). In contrast, a strong increase of $\mathrm{H} 3 \mathrm{~K} 4 \mathrm{Me} 3$ in $\beta$-catenin KO ECs was observed in the promoter region of Cypla1 (Fig. 2D).

To test whether conditions known to augment $\beta$-catenin transcription could lead to Cyp1b1 expression, we compared subconfluent with confluent ECs (Goodwin et al., 2006). Assessment of Cyp $1 b 1$ and Cypla1 expression at different cell densities revealed increased $C y p 1 b 1$ transcription in subconfluent $\beta$-catenin WT, but not in $\beta$-catenin KO ECs (Fig. 3A). The expression of Cypla1 and Ahr, however, was not affected by cell density (Fig. $3 B, C)$. Along the same line, we analyzed whether the effect of 
A
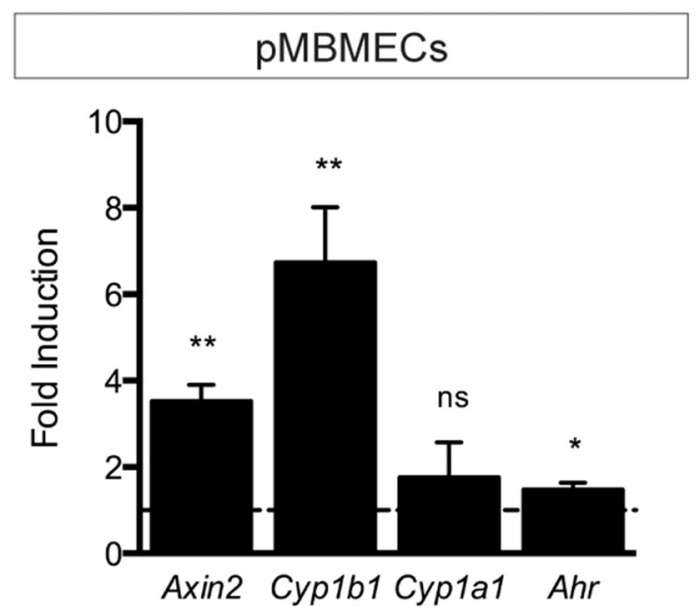

C
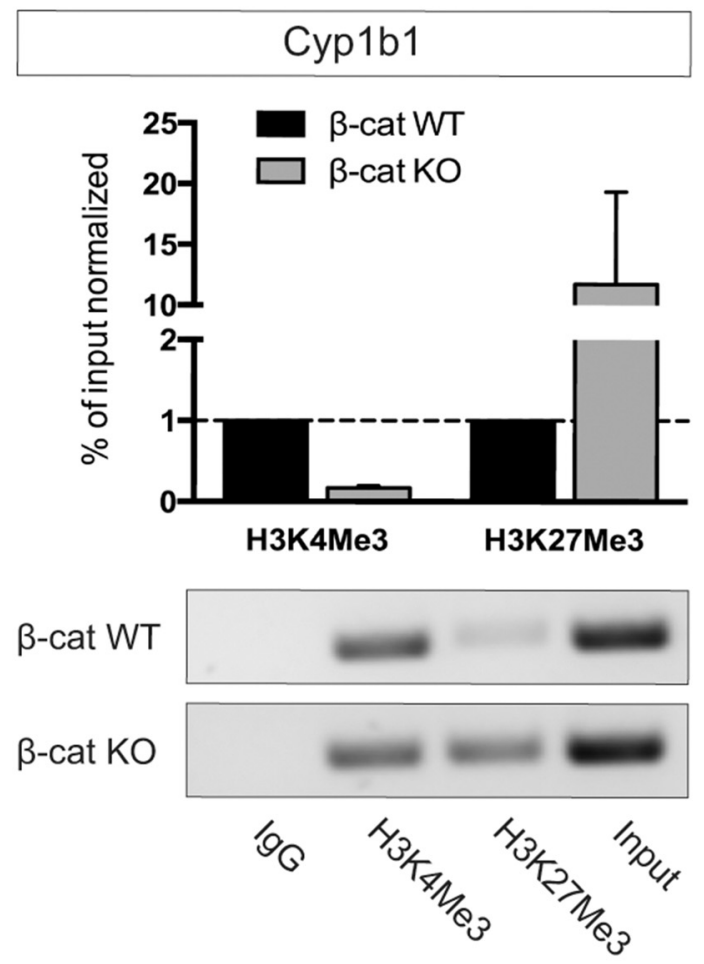

B

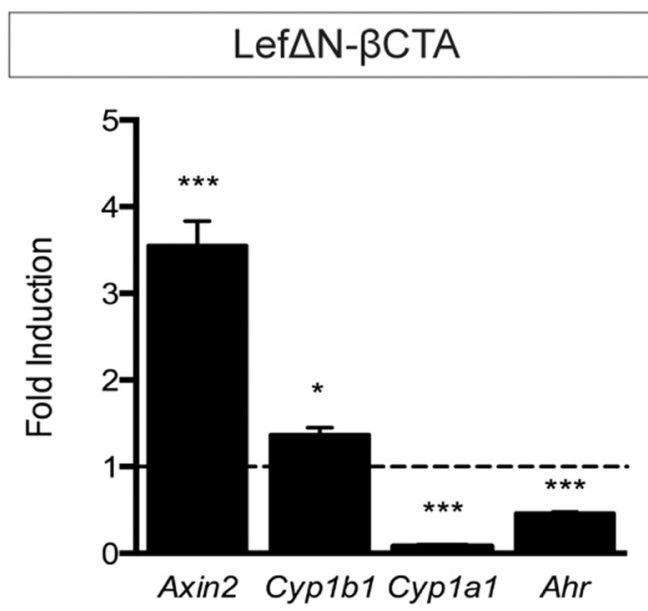

D
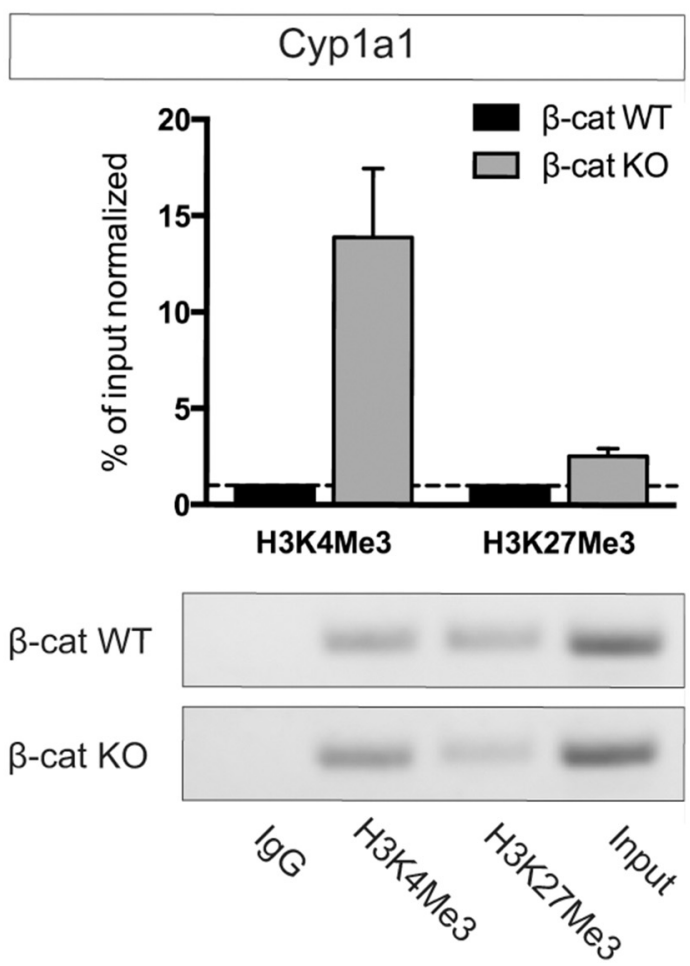

Figure 2. $\quad \beta$-Catenin transcriptional activity oppositely regulates Cyp1b1 and Cyp 1b1 expression in ECs. A, qRT-PCR of pMBMECs stimulated with Wnt $3 a \mathrm{C} C M$ for $5 \mathrm{~d}$ relative to control CM (dashed line, $n=4$ ). $\boldsymbol{B}$, mRNA expression of Axin2, Cyp 161, Cyp 1a1, and Ahr in $\beta$-catenin KO ECs transduced with Lef $\Delta \mathrm{N}-\beta C T$ A relative to the vector control (dashed line, $n=3) .{ }^{*} p<0.05$. ${ }^{* *} p<0.01$. ${ }^{* * *} p<0.001$. ns, Not significant. Error bars indicate SEM. C, D, ChIP analysis of $\beta$-catenin WT and KO ECs determining the enrichment of either activating (trimethylation of histone H3 at lysine 4: H3K4Me3) or repressive (trimethylation of histone H3 at lysine 27: H3K27Me3) chromatin marks in Cyp1b1 (C) and Cyp1a1 (D) promoter regions. Quantitative ChIP-qPCR data are calculated as percentage over input normalized to $\beta$-catenin WT condition, which is assumed as 1 (dashed line). Columns represent mean \pm SEM of two ChIP experiments. PCR products were visualized on agarose gels for qualitative analysis.

shear stress, known to regulate Cyp1b1 and Cyp1a1 expression (Conway et al., 2009), could also be dependent on $\beta$-catenin, given that the onset of flow leads to junctional reorganization going along with $\beta$-catenin dissociation and transcriptional activity (Norvell et al., 2004). Indeed, Cyp1b1 expression was significantly increased by exposure to fluid shear stress only in $\beta$-catenin WT ECs, whereas shear exclusively upregulated Cypla1 in $\beta$-catenin KO ECs. Transcription of Ahr did not change upon exposure to shear stress in either of the two cell lines (Fig. 3D).

\section{VE-cadherin deficiency upregulated $C y p 1 b 1$ expression} independently of $\mathrm{Ahr}$

To further characterize the impact of Wnt/ $\beta$-catenin signaling on Cyp1b1 expression, we made use of an EC line lacking VE-cadherin $\left(\mathrm{Cdh} 5^{--}\right)$and the corresponding control line that was reconstituted with WT human VE-cadherin cDNA (Taddei et al., 2008). Taddei et al. could show that Cdh $5^{-l-}$ ECs demonstrate higher levels of nuclear $\beta$-catenin compared with controls going along with increased transcriptional activity. Interestingly, Cyp 1 b1 expression was significantly increased in $\mathrm{Cdh} 5^{-1-}$ ECs, 
A

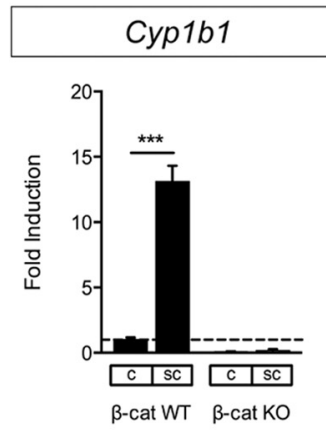

E
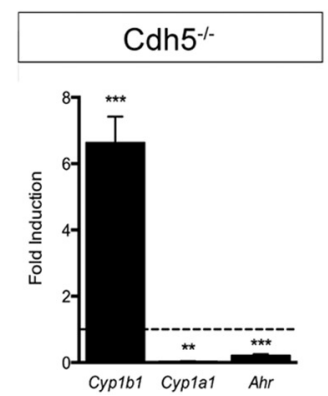

B

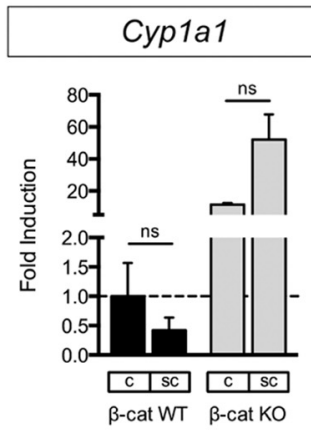

F

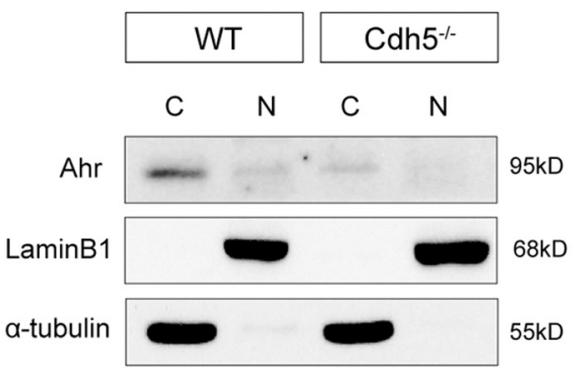

C

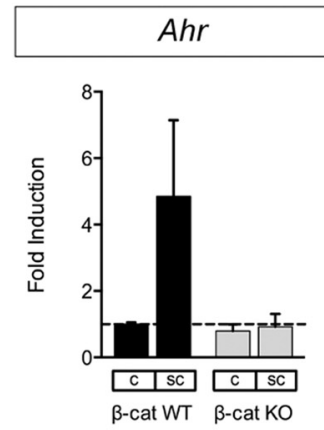

D

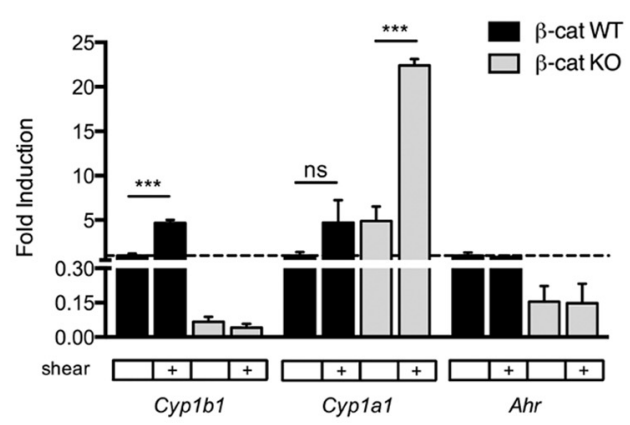

Figure 3. Subconfluent and VE-cadherin-deficient ECs upregulate Cyp1b1 transcription independently of Ahr. $\boldsymbol{A}-\boldsymbol{C}, \mathrm{qRT}$-PCR for Cyp1b1 (A), Cyp 1a1 (B), and Ahr (C) in $\boldsymbol{\beta}$-catenin WT and K0 ECs under confluent ( $c$ ) and subconfluent (sc) culture conditions. mRNA levels are shown relative to expression in confluent $\beta$-catenin WT ECs (dashed line, $n=3$ ). $D$, qRT-PCR of $\beta$-catenin WT and KO ECs under static or shear conditions (12 dynes $/ \mathrm{cm}^{2}, 24 \mathrm{~h}$ ). mRNA levels are shown relative to expression in static $\beta$-catenin WT ECs (dashed line, $n=3$ ). E, qRT-PCR for Cyp 1b1, Cyp 1a1, and Ahr in VE-cadherin-deficient ( $\mathrm{Cdh} 5^{-/-}$) ECs relative to $\mathrm{Cdh} 5^{-/-}$ECs reinfected with human VE-cadherin (dashed line, $\left.n=5\right)$. $\boldsymbol{F}$, Western blot for Ahr protein expression in cytosolic $(\mathrm{C})$ and nuclear $(\mathrm{N}$ ) fraction of $\mathrm{Cdh} 5^{-/-}$ECs and Cdh5 ${ }^{-/-}$ECs reinfected with human VE-cadherin (WT). LaminB1 and $\alpha$-tubulin are shown as controls for nuclear and cytosolic protein loading, respectively. $\mathbf{G}$,

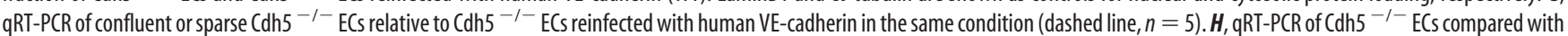
Cdh5 ${ }^{-1-}$ ECs reinfected with human VE-cadherin (dashed line) under static conditions and after exposure to shear stress $(n=4) .{ }^{*} p<0.05 .{ }^{* *} p<0.01 .{ }^{* * *} p<0.001$. ns, Not significant. Error bars indicate SEM.

whereas Cyplal as well as Ahr were downregulated (Fig. 3E). Western blot analyses were performed to determine whether the augmented transcription of Cyp1b1 could be related to Ahr activity, which would go along with its nuclear translocation. However, nuclear as well as cytoplasmic Ahr protein levels were decreased in Cdh5 ${ }^{-1-}$ ECs compared with control (Fig. $3 F$ ). Analyzing whether cell confluency could exert additional effects on Cyp transcription in Cdh5 $5^{-1-}$ ECs, we observed a further increase in Cyp1b1 expression under subconfluent conditions in Cdh5 ${ }^{-1-}$ ECs versus control. However, cell confluency did not have any impact on Cyplal or Ahr expression in Cdh5 ${ }^{-1-}$ ECs (Fig. 3G). Exposure to shear stress had similar effects, leading to increased Cyp $1 b 1$ transcription in Cdh5 ${ }^{-1-}$ ECs compared with static cultures (Fig. $3 H$ ). Neither Cyplal nor Ahr transcription was changed after exposure of Cdh $5^{-1-}$ ECs to shear.

\section{Noncanonical Wnt pathways showed only moderate impact on Cyp1b1 regulation in ECs in vitro}

To understand whether noncanonical Wnt signaling additionally might play a role in the regulation of $C y p 1 b 1$, we stimulated pMBMECs with conditioned medium containing the noncanonical ligand Wnt5a and analyzed transcription levels of the canonical targets Axin2 and Cyp1b1. Wnt5a tended to reduce the expression of Axin 2 and moderately, but significantly, decreased Cyp1b1 transcription (Fig. 4A). To distinguish between the Wnt/ PCP and the $\mathrm{Ca}^{2+}$-dependent pathway, we analyzed the downstream effectors C-Jun-N-terminal kinase 1 (JNK1) and nuclear factor of activated T-cells (NFAT), respectively. Comparing $\beta$-catenin KO with WT ECs for noncanonical Wnt/PCP pathway activation revealed a greater amount of phosphorylated and therefore active JNK in $\beta$-catenin KO ECs. In contrast, levels of the nonphosphorylated form of NFAT1, a mediator of the noncanonical Wnt/ $\mathrm{Ca}^{2+}$ pathway, were decreased in $\beta$-catenin $\mathrm{KO}$ ECs (Fig. 4B). However, inhibition of JNK and NFAT1 in WT ECs did not result in significant effects on Cyp $1 b 1$ expression levels (Fig. 4C), suggesting that noncanonical pathways are not directly involved in $C y p 1 b 1$ regulation. Interestingly, Cypla1 was upregulated following calcineurin inhibition by cyclosporin A (CsA) that acts upstream of NFAT, whereas Cyp1b1 was downregulated upon JNK1 inhibition by SP600125 (Fig. 4C).

\section{$\boldsymbol{\beta}$-Catenin was indispensable for Ahr-mediated induction of Cyp1b1, but not Cyp1a1 expression}

To determine whether the Ahr-mediated regulation of Cyp expression is also dependent on $\beta$-catenin or whether both transcription factors can be considered as independent regulators of Cyp1b1, Ahr nuclear translocation and transcriptional activity were induced by stimulating $\beta$-catenin WT and KO ECs with the Ahr agonist TCDD. In $\beta$-catenin WT ECs, TCDD treatment significantly increased Cyp $1 b 1$ transcription, an effect not observed in $\beta$-catenin KO ECs (Fig. $5 A$ ). In contrast, Cyp 1al expression was only increased by TCDD in $\beta$-catenin KO ECs (Fig. $5 B$ ). Concomitant inhibition of Ahr by treatment with the antagonist $\mathrm{CH}-223191$ abrogated the TCDD-induced Cyp $1 b 1$ expression in $\beta$-catenin WT ECs (Fig. $5 A)$. Interestingly, Ahr inhibition alone did not have any effect 
A

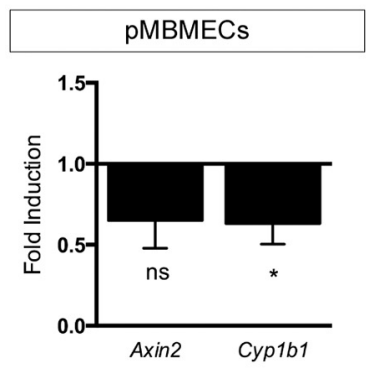

B

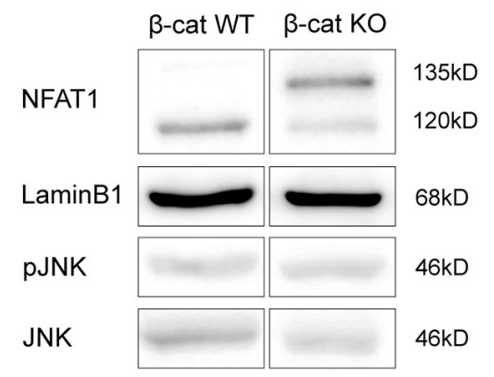

C

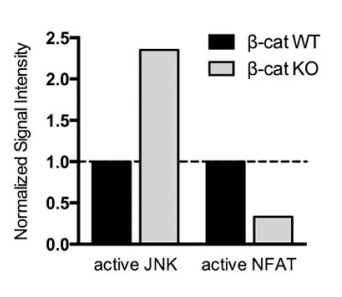

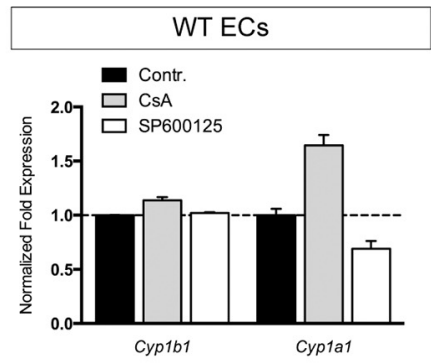

Figure 4. Noncanonical Wnt signaling is not able to increase, but rather decreases Cyp1b1 expression in ECs. A, qRT-PCR for Axin2 and Cyp $1 b 1$ in pMBMECs stimulated with Wnt5a CM for $5 \mathrm{~d}$ relative to control CM $(n=3)$. B. Western blot for JNK and p-JNK as well as NFAT1 in $\beta$-catenin WT and $\beta$-catenin KO ECs. NFAT1 represents both the phosphorylated, inactive (135 kDa) as well as the dephosphorylated, active $(120 \mathrm{kDa}$ ) protein. LaminB1 served as loading control. Quantification shows normalized signal intensity of p-JNK relative to JNK as well as of active NFAT. Signal intensity in $\beta$-catenin KO ECs are shown relative to $\beta$-catenin WTECs (dashed line). ${ }^{*} p<0.05 .{ }^{* *} p<0.01 .{ }^{* * *} p<0.001$. ns, Not significant. C, qRT-PCR for Cyp $1 b 1$ and Cyp $1 a 1$ in $\beta$-catenin WT ECs treated with EtOH (Contr.), $1 \mu \mathrm{M}$ CSA, or $20 \mu \mathrm{M}$ SP600125 for $1 \mathrm{~h}(n=2)$. Error bars indicate SEM.

A

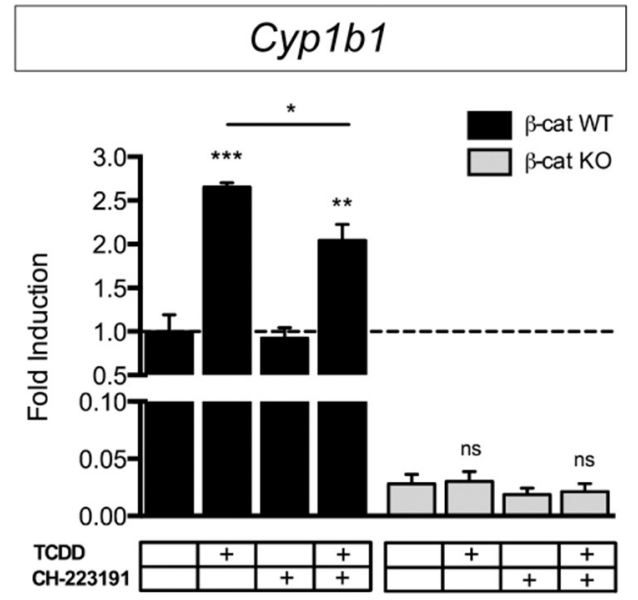

B

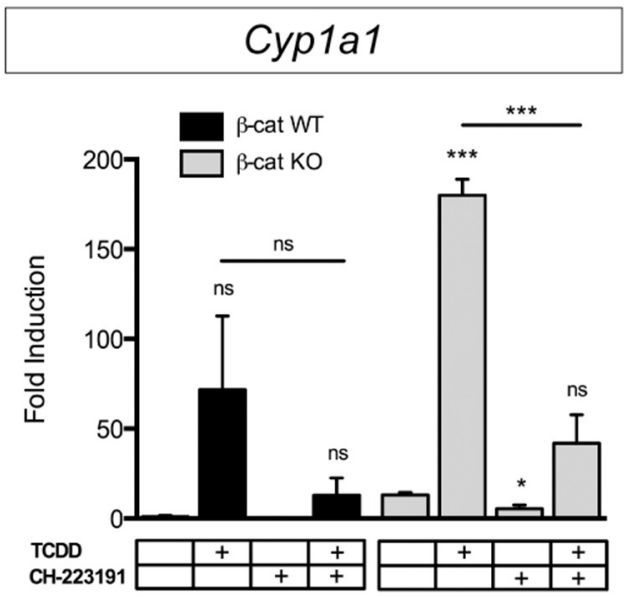

Figure 5. Ahr-induced expression of Cyp 1b1 is dependent on $\beta$-catenin, whereas Cyp1a1 transcription is not. qRT-PCR analysis for Cyp 1b1 (A) and Cyp 1a1 (B) in $\beta$-catenin WT and $\beta$-catenin K0 ECs stimulated with $25 \mathrm{~nm}$ TCDD for $7 \mathrm{~h}$ in combination with $10 \mu \mathrm{m}$ CH-223191 ( $n=5$ ). Expression levels of $\beta$-catenin WT ECs under control conditions were defined as 1 (dashed line). ${ }^{*} p<0.05$. ${ }^{* *} p<0.01 .{ }^{* * *} p<0.001$. ns, Not significant. Error bars indicate SEM.

on mRNA levels, indicating that Ahr is dispensable for maintaining Cyp $1 b 1$ transcription. $\beta$-Catenin KO ECs did not show any changes in expression levels following any of the treatments (Fig. 5A). Transcription of Cyplal was decreased by Ahr inhibition in $\beta$-catenin KO ECs. Furthermore, elevated Cypla1 mRNA levels after TCDD treatment were reduced by Ahr inhibition in $\beta$-catenin KO ECs (Fig. $5 B$ ).

As Cyp1b1-deficient mice demonstrate abnormal retinal angiogenesis (Tang et al., 2009) and as $\beta$-catenin-deficient ECs only form disorganized aggregates on Matrigel (Cattelino et al., 2003), we wanted to determine whether the effects in $\beta$-catenin KO ECs can be attributed to Cyp1b1 alone as a bona fide downstream target of $\beta$-catenin.

Cyp1b1 was unable to promote capillary morphogenesis in the absence of $\boldsymbol{\beta}$-catenin

To study the angiogenic potential of Cyp $1 \mathrm{~b} 1$, we generated EC lines reexpressing WT murine $\beta$-catenin $(\beta$-cat $\mathrm{KO}+\beta$-cat $)$ or Cyp1b1 ( $\beta$-cat $\mathrm{KO}+\mathrm{Cyp} 1 \mathrm{~b} 1)$ in the $\beta$-catenin $\mathrm{KO}$ background. Protein expression was confirmed by Western blot analysis, preceded by immunoprecipitation for Cyp1b1 from the Cyp1b1reinfected cells (Fig. 6A,B). Cord formation assays on Matrigel revealed that, although reinfection of $\beta$-catenin restored protein levels only by $13 \%$ of the WT, this amount was sufficient to significantly rescue cord-forming capability (Fig. 6C, $D, G$ ). However, $C y p 1 b 1$ reexpression was not able to rescue capillary morphogenesis, resembling the $\beta$-catenin $\mathrm{KO}$ conditions by forming isolated cell aggregates with only rare, single-cell branches (Fig. $6 E-G$ ). To evaluate the contribution of Cyp 1 b1 to cord formation, we treated $\beta$-catenin WT ECs with the Cyp $1 \mathrm{~b} 1$ inhibitor TMS, which decreased the number of branches in WT ECs compared with controls (Fig. 6H).

To further understand the function of Cyp1b1 specifically in brain ECs, we investigated the metabolizing function of Cyp1b1 of endogenous substrates.

\section{Cyp1b1 modulated BBB properties in ECs by metabolizing retinol to $R A$}

One well-described function of CYP1 family members is the biosynthesis of atRA from retinol (RO), independent of the retinaldehyde dehydrogenase (RALDH1-3)-dependent pathway (Chen et al., 2000). Recently, it could be shown that RA increases the expression of Pgp as well as the junction proteins VE-cadherin and occludin (Ocln) in human and mouse brain ECs, leading to improved barrier properties (Mizee et al., 2013). We could confirm the upregulation of Ocln by atRA treatment in $\beta$-catenin 
WT ECs as well as of Pgp in $\beta$-catenin WT and KO ECs (Fig. 7A). To unravel the role of Cyp1b1 in RA synthesis, we determined Pgp expression in $\beta$-catenin WT, $\mathrm{KO}$, as well as Cyp1b1-infected KO ECs after RO treatment, revealing significant upregulation of Pgp mRNA levels in $\beta$-catenin WT and KO ECs reexpressing Cyp1b1 (Fig. $7 B)$. Immunofluorescence staining confirmed increased Pgp protein levels in $\beta$-catenin WT as well as $\beta$-catenin $\mathrm{KO}$ ECs reinfected with Cyp1b1 after RO treatment, whereas $\beta$-catenin KO ECs did not show an increase in Pgp (Fig. 7C,D). Consistent with the expression data, the cellular retention of the Pgp substrate rhodamine-123 was significantly decreased in $\beta$-catenin WT ECs as well as in $\beta$-catenin KO ECs reexpressing Cyp1b1 (Fig. 7E), indicating that Cyplb1-mediated conversion of RO to RA influences Pgp expression and function.

\section{Cyp1b1 induced 20-HETE production in ECs, which influences junction protein expression and increases permeability}

Other pathways that are predominantly modulated by the enzymatic activity of CYP enzymes are the metabolic cascades converting polyunsaturated fatty acids into lipid metabolites, which are highly relevant for cell physiology. To determine whether Cyp1b1 function might be considered responsible for the synthesis of one or the other metabolite, $\beta$-catenin WT and KO ECs as well as KO ECs reinfected with Cyp1b1 were treated with TMS to specifically inhibit Cyp1b1. At the same time, cells were incubated with AA, EPA, and DHA, and cell supernatants were analyzed for lipid metabolites by LC-MS/MS lipid profiling. Most strikingly, the concentration of AA-derived 20-HETE was significantly lower in $\beta$-catenin KO compared with WT ECs. Furthermore, reexpression of Cyp1b1 in $\beta$-catenin KO ECs was able to fully rescue 20-HETE levels, whereas Cyp1b1 inhibition reversed this effect (Fig. 8A). To further investigate the potential effects of 20 HETE on the endothelium, we were interested in whether 20 HETE has any influence on barrier properties. Interestingly, 20HETE-treated pMBMECs revealed a decrease in TEER and, concomitantly, increased $\mathrm{Ccl}$, indicating impairment of junctional integrity (Fig. 8B,C). These effects became apparent already after $24-26 \mathrm{~h}$, and differences persisted beyond the plateau phase (Fig. 8B). Detailed analyses of TEER as well as $\mathrm{Ccl}$ values of two selected time points evidenced statistical significance (Fig. 8C). To determine whether the differences in TEER and Ccl can be attributed to changes in paracellular permeability, we analyzed tracer flux across the cell monolayer. Indeed, 20-HETE increased flux of differently sized tracers (Fig. $8 D$ ). To understand whether
B
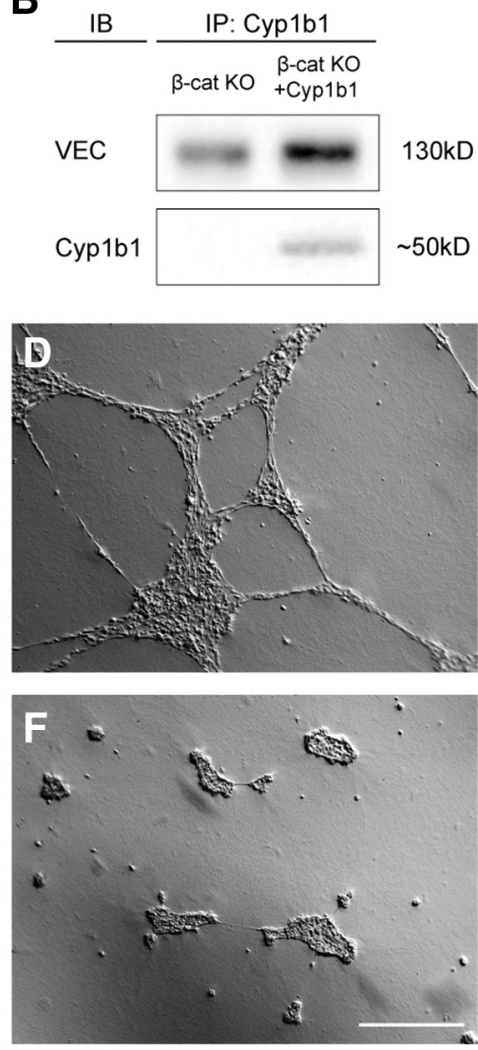

H

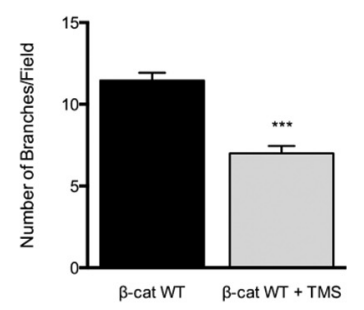

Figure 6. Cyp1b1 does not rescue capillary morphogenesis in $\beta$-catenin-deficient ECs. $\boldsymbol{A}$, Western blot for $\beta$-catenin in $\beta$-catenin WT, $\beta$-catenin KO reinfected with WT mouse $\beta$-catenin, and $\beta$-catenin KOECs. $\alpha$-Tubulin served as loading control. $\boldsymbol{B}$, Western blot of immunprecipitated Cyp1b1 in $\beta$-catenin KO ECs and Cyp1b1-infected $\beta$-catenin KO ECs. VE-cadherin was used as loading control. $\boldsymbol{C}-\boldsymbol{F}$, Representative pictures of $\beta$-catenin WTECs $(\boldsymbol{C}, \beta$-catenin KOECs reinfected with WT murine $\beta$-catenin (D), $\beta$-catenin KO ECs infected with LaCZ as control $(\boldsymbol{E})$, or $\beta$-catenin KO ECs infected with human Cyp1b1 $(\boldsymbol{F})$ grown on Matrigel basement membrane matrix for $18 \mathrm{~h}$. Scale bar, $500 \mu \mathrm{m}$. G, Statistical analysis representing number of branches per field $(n=3)$ $\boldsymbol{H}, \beta$-Catenin WT ECs were stimulated with $5 \mu \mathrm{M}$ TMS and were grown on Matrigel basement membrane for $18 \mathrm{~h}$. Statistical analysis represents number of branches per field of three independent experiments. Experiments were performed in duplicates; 4 pictures were taken and analyzed, respectively. ${ }^{* * *} p<0.001$. Error bars indicate SEM.

this effect correlates with changes in junction protein organization, we stained the same filter inserts for the tight junction proteins ZO- 1 as well as Cldn5, revealing decreased expression after 20-HETE treatment (Fig. 8E). Ocln protein levels did not show any remarkable differences (Fig. $8 F$ ). To assess whether the changes in permeability might additionally be attributed to transcellular transport, protein expression of caveolin was investigated, revealing no significant differences (Fig. $8 F$ ). Additionally, concentration-dependent effects of 20-HETE on junction protein expression were investigated in mouse brain endothelioma cells, revealing a significant increase in VE-cadherin only at the lowest concentration of $10 \mathrm{~nm}$ (Fig. 9A). However, the tight junc- 
A

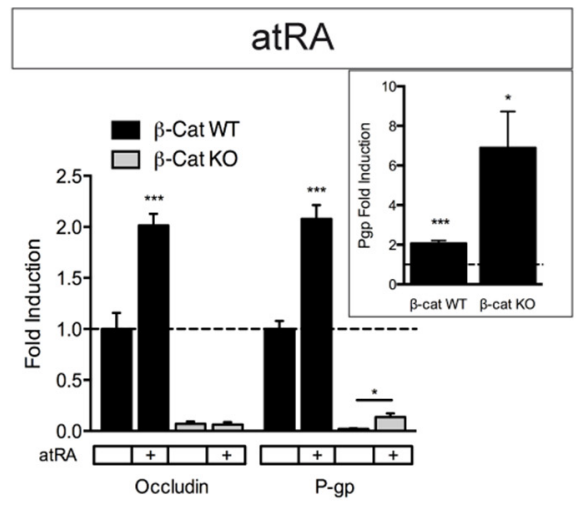

B
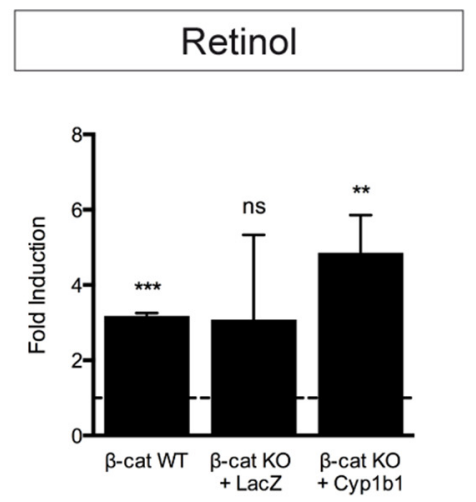

C
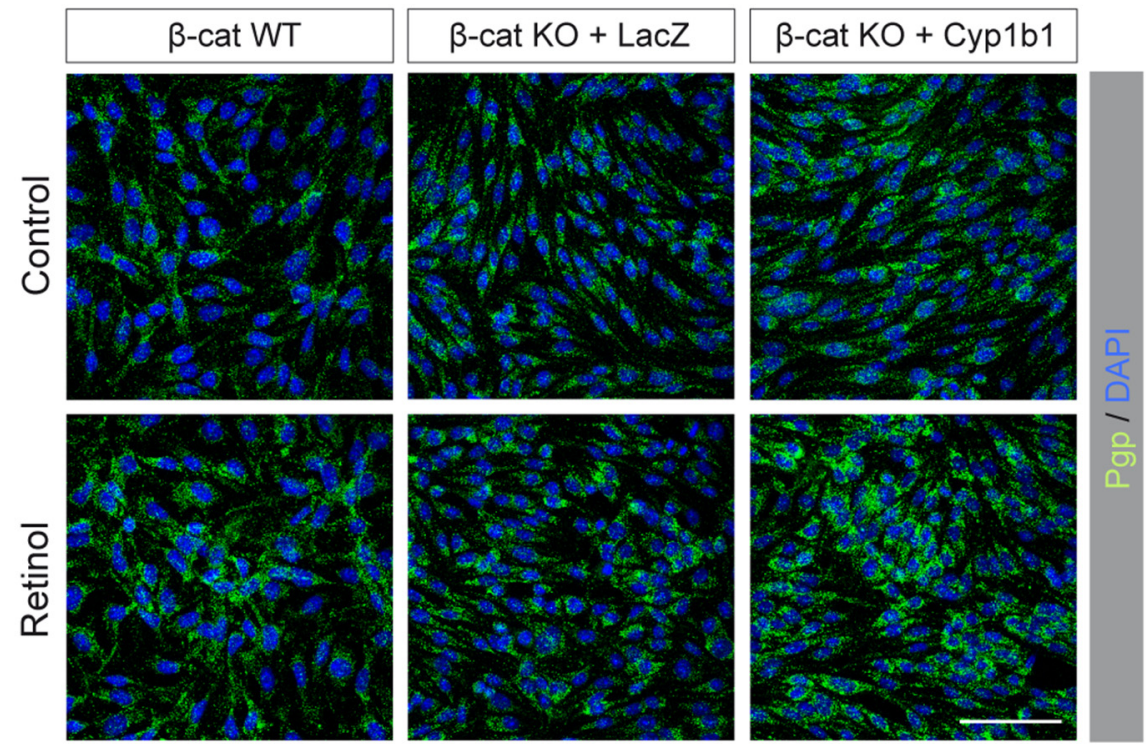

D

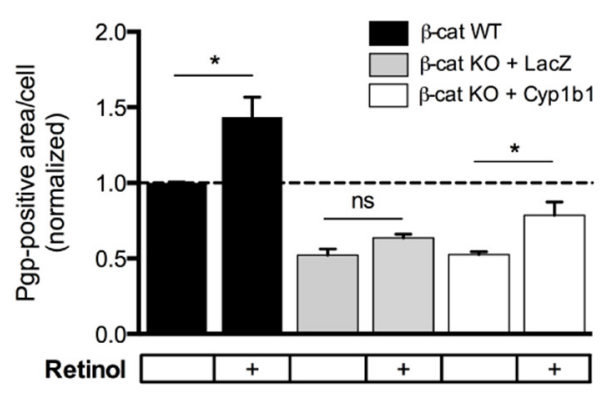

E

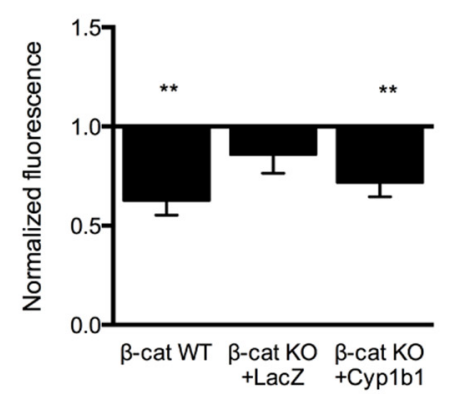

Figure 7. Cyp1b1-mediated metabolism of retinol increases Pgp expression and activity. A, qRT-PCR analysis for Ocln and Pgp in $\beta$-catenin WT and $\beta$-catenin $\mathrm{KO} \mathrm{ECS}$. Cells were treated with $5 \mu \mathrm{m}$ atRA for $48 \mathrm{~h}$. Expression levels are shown relative to control (dashed line, $n=5$ ). Inlay represents Pgp expression in $\beta$-catenin WT and $\beta$-catenin KO ECs after atRA treatment. $\boldsymbol{B}$, qRT-PCR for $P g p$ in $\beta$-catenin WT, $\beta$-catenin KO infected with LaCZ as control and $\beta$-catenin KO ECs reinfected with Cyp1b1. ECs were treated with $5 \mu \mathrm{m}$ retinol for $72 \mathrm{~h}$. Expression levels under control conditions were defined as $1(n=4)$. $C$, Representative pictures of immunofluorescence stainings for Pgp on $\beta$-catenin WT, $\beta$-catenin KO infected with LaCZ and $\beta$-catenin KO ECs reinfected with Cyp1b1. Treatment was the same as for $\boldsymbol{B}(n=3,10$ pictures/condition). Scale bar, $100 \mu \mathrm{m}$. $\boldsymbol{D}$, Quantification of Pgp-positive area per cell relative to $\beta$-catenin WTECs under control condition based on IF staining. $E$, Rhodamine- 123 efflux assay of $\beta$-catenin WT, LacZ- and Cyp1b1-infected $\beta$-catenin K0 ECs treated with $5 \mu \mathrm{m}$ retinol for $72 \mathrm{~h}(n=5)$. Bars represent normalized fluorescence relative to untreated. ${ }^{*} p<0.05 .{ }^{* *} p<0.01 .{ }^{* * *} p<0.001$. ns, Not significant. Error bars indicate SEM.

tion protein Ocln was constant under all conditions (Fig. 9B). Similarly, caveolin protein expression did not change upon stimulation with $10 \mathrm{~nm}$ 20-HETE (Fig. 9C), mimicking the effects in pMBMECs.
Systemic inhibition of Cyp1b1 by TMS in vivo increased $\mathrm{BBB}$ permeability

To investigate the role of Cyp $1 \mathrm{~b} 1$ at the $\mathrm{BBB}$ in vivo, we inhibited Cyp1b1 in WT C57BL/ 6/JRJ mice by TMS injection on four consecutive days. Animals remained phenotypically normal for the time of the treatment. Mice were injected by a mix of FTSC $(0.4 \mathrm{kDa})$ and TMR-dextran $(3 \mathrm{kDa})$ tracers on the fourth day before they were killed (Fig. 10A). Fluorescence spectroscopic measurement of FTSC and TMR-dextran tracers in the brain parenchyma revealed that Cyp1b1 inhibition led to increased tracer permeability specifically in brain vessels, whereas permeability in the kidney remained unchanged (Fig. 10A,B).

\section{Glioma vessels showed reduced Cyp1b1} expression, being accompanied by decreased RA signaling

As many brain pathologies and brain glioma in particular go along with compromised $\mathrm{BBB}$ integrity caused by altered junction protein expression as well as impaired transporter function, we aimed to investigate whether $C y p 1 b 1$ might be regulated under glioma conditions. Therefore, GL261 mouse glioma cells were intracranially transplanted into NMRINUDE mice and the vasculature was analyzed comparing the tumor-bearing with the contralateral hemisphere (Fig. $11 A$ ). As shown previously, ColIV staining revealed normal vessels in the contralateral hemisphere, whereas the tumor vessels exhibited a highly distorted morphology (Fig. 11B) (Reis et al., 2012). Interestingly, comparing total lysates from the tumor-bearing and the contralateral hemisphere by qRTPCR analysis revealed decreased expression of Axin2, Cyp 1b1, and Ahr but also of the RA target genes Rar $\beta$, Ocln, and $P g p$ (Fig. 11C). The angiogenesisrelated gene Ang2, however, was upregulated in the glioma hemisphere. These data could additionally be confirmed in isolated tumor microvessels (data not shown).

\section{Discussion}

The $\mathrm{BBB}$ protects the brain from endogenous and exogenous substances that are incompatible with neuronal function or survival. Endothelial barrier function in the CNS is induced by the canonical Wnt/ $\beta$-catenin pathway that regulates barrier-related genes in BBB microvessels (Engelhardt and Liebner, 2014). Although so far BBB research focused mostly on the regulation of junction molecules and transporter systems, metabolic pathways receive increasing attention in vascular biology and in CNS vessels (Eelen et al., 2015). 
A

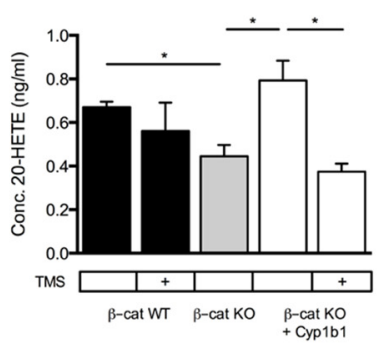

C

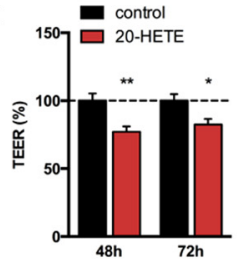

B

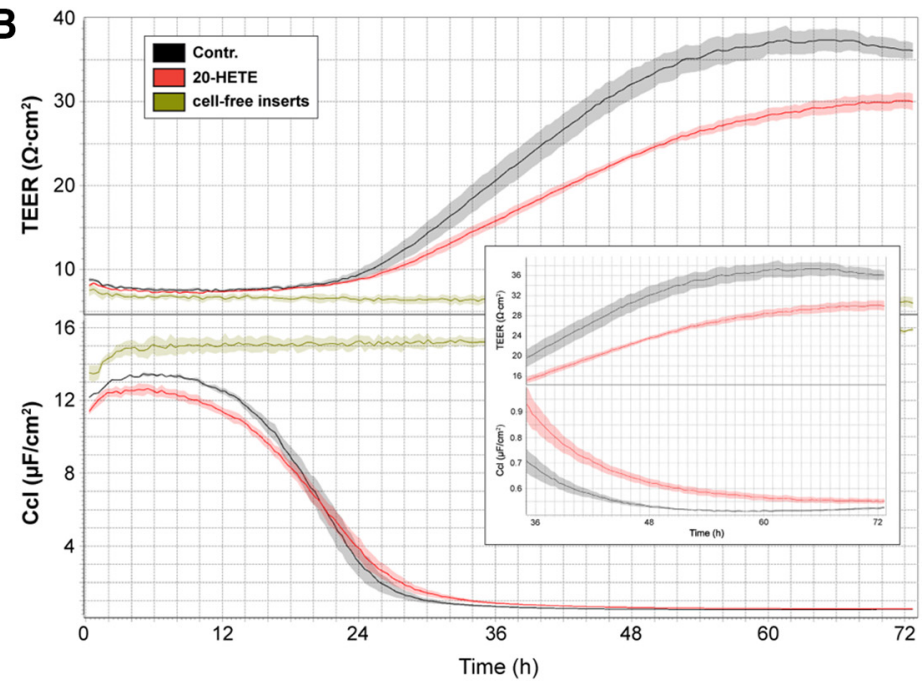

D
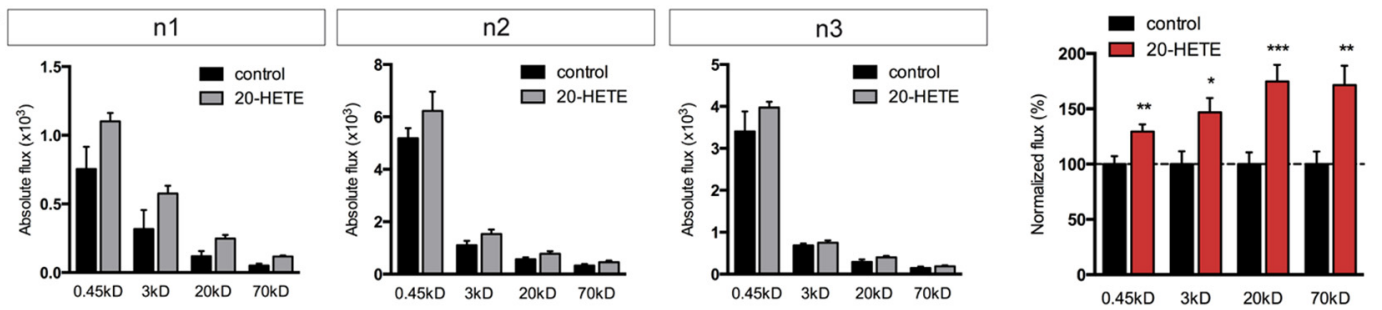

E
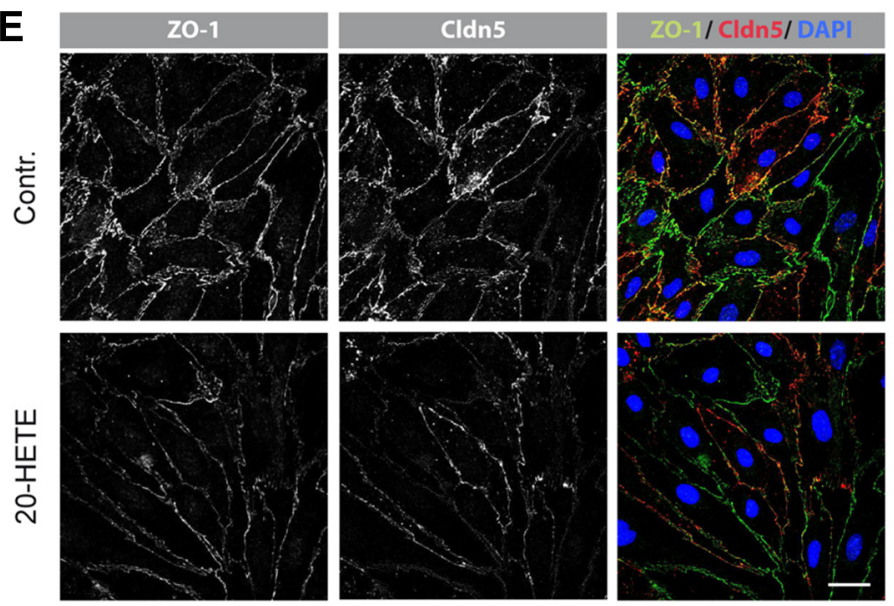
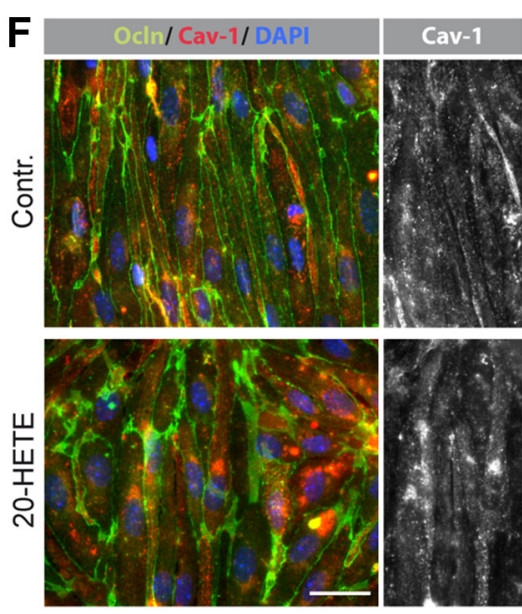

Figure 8. Cyp1b1 enzymatic activity modulates endothelial barrier function by influencing lipid metabolism. $A$, Levels of 20-HETE in the supernatant of $\beta$-catenin WT, LacZ- and Cyp1b1-infected $\beta$-catenin KO ECs after treatment with $10 \mu \mathrm{m}$ arachidonic acid for $24 \mathrm{~h}$ with or without $5 \mu \mathrm{M}$ TMS for $27 \mathrm{~h}(n=3)$. B, Representative TEER and CCl data of pMBMECs treated with $10 \mathrm{nM} 20$-HETE. Confluent cells were monitored for $72 \mathrm{~h}$. Inlay represents a magnification of the course of TEER and Cl values from 36 to $72 \mathrm{~h}$. Cell-free inserts were used as internal control. $C$, Statistical analysis of TEER (top) and Cl (bottom) values at 48 and $72 \mathrm{~h}$ calculated as percentage of control (dashed line, $n=3$ ). D, Tracer assay performed after $72 \mathrm{~h}$ of stimulation with the same cells as used for $\boldsymbol{B}, \boldsymbol{C}$. Flux of $0.45 \mathrm{kDa}$ Lucifer yellow, TXR $3 \mathrm{kDa}$-dextran, TMR $20 \mathrm{kDa}$-dextran, and FITC $70 \mathrm{kDa}$-dextran $1 \mathrm{~h}$ after tracer administration are shown as absolute values for each individual experiment and in percentage relative to control condition (dashed line) representing means of all three experiments. ${ }^{*} p<0.05 .{ }^{* *} p<0.01 .{ }^{* * *} p<0.001$. Error bars indicate SEM. $\boldsymbol{E}$, Representative pictures of immunofluorescence stainings for Z0-1 and Cldn5. Scale bar, $50 \mu \mathrm{m}$. $\boldsymbol{F}$, Representative pictures of immunofluorescence stainings for 0cln and caveolin (Cav-1). Scale bar, $20 \mu \mathrm{m}$. Stainings were performed on the same cells used for $\boldsymbol{B}, \boldsymbol{C}, \boldsymbol{D}$.

In an Affymetrix screen performed to identify novel targets of the Wnt/ $\beta$-catenin pathway in ECs, Cyp1b1 was one of the strongly downregulated genes in $\beta$-catenin KO ECs. Cyplb1 is the major Cyp gene expressed in human brain microvessels and only poorly expressed in nonbarrier ECs (Dauchy et al., 2008). The homologs Cypla1 and Cyp1b1 are regulated by shear stress in an Ahrdependent manner (Conway et al., 2009), whereas in non-ECs they depend on the concomitant activation of Ahr and $\beta$-catenin (Braeuning et al., 2011; Procházková et al., 2011). However, the $\beta$-catenin-dependent regulation and function of Cyp1b1 in endothelia of the CNS remained elusive.
The results of the present study reveal the direct and specific transcriptional regulation of $C y p 1 b 1$ by $\beta$-catenin, whereas Cypla1 is absent in WT ECs but becomes upregulated in $\beta$-catenin KO ECs, suggesting a compensatory regulation (Fig. $1 D$ ). Reexpression of Cyp $1 b 1$ in $\beta$-catenin KO ECs rescued Cyp1b1 levels and restored the low levels of Cyp1a1, suggesting that the expression of these CYP1 members is mutually exclusive in ECs.

The finding that inducers of $C y p 1 b 1$, such as subconfluency, shear stress, and Ahr activation failed to augment Cyp $1 b 1 \mathrm{mRNA}$ in $\beta$-catenin KO ECs further supports the crucial role of $\beta$-catenin. In contrast, Cypla1 was only regulated by these induc- 
A

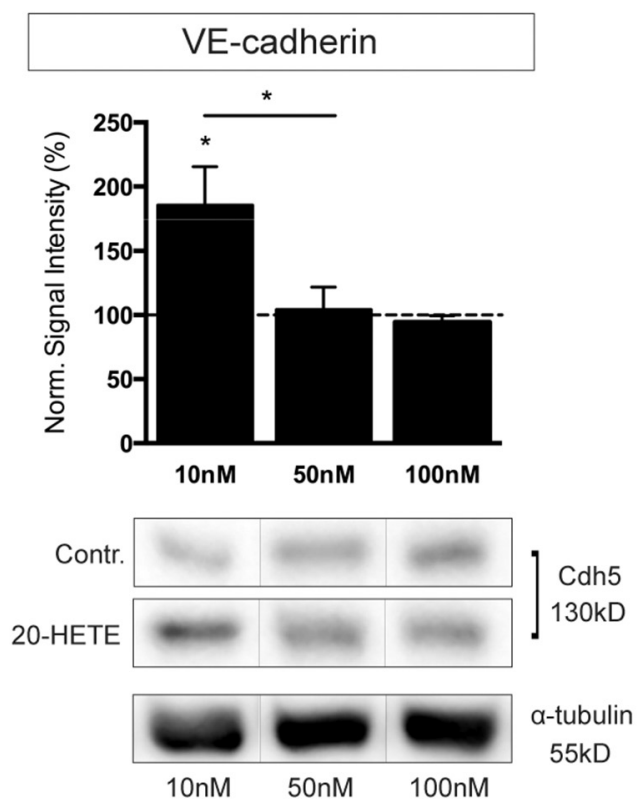

C

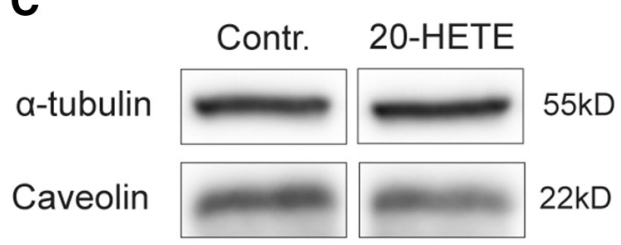

B
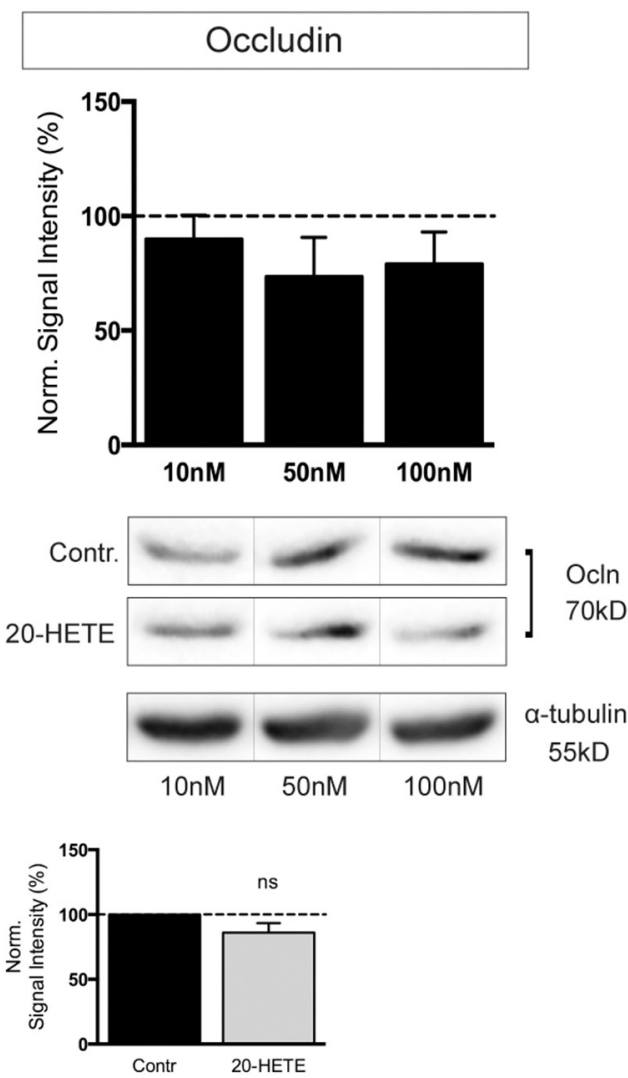

Figure 9. 20-HETE modulates junction protein expression. Quantification and representative Western blots for VE-cadherin (Cdh5) $(\boldsymbol{A})$ and occludin $(0 \mathrm{Cln})(\boldsymbol{B})$ in mouse brain ECs after treatment with 10,50, and $100 \mathrm{~nm} 20$-HETE for $24 \mathrm{~h}$. Protein levels after 20-HETE treatment were normalized to protein levels of control condition, respectively (dashed lines). $\alpha$-Tubulin is shown as loading control. Data represent means of four or five independent experiments. $\boldsymbol{C}$, Western blots and quantification for caveolin in mouse brain ECs after treatment with 10 nм 20-HETE for $24 \mathrm{~h}(n=3) .{ }^{*} p<0.05 .{ }^{* *} p<0.01 .{ }^{* * *} p<0.001$. ns, Not significant. Error bars indicate SEM.
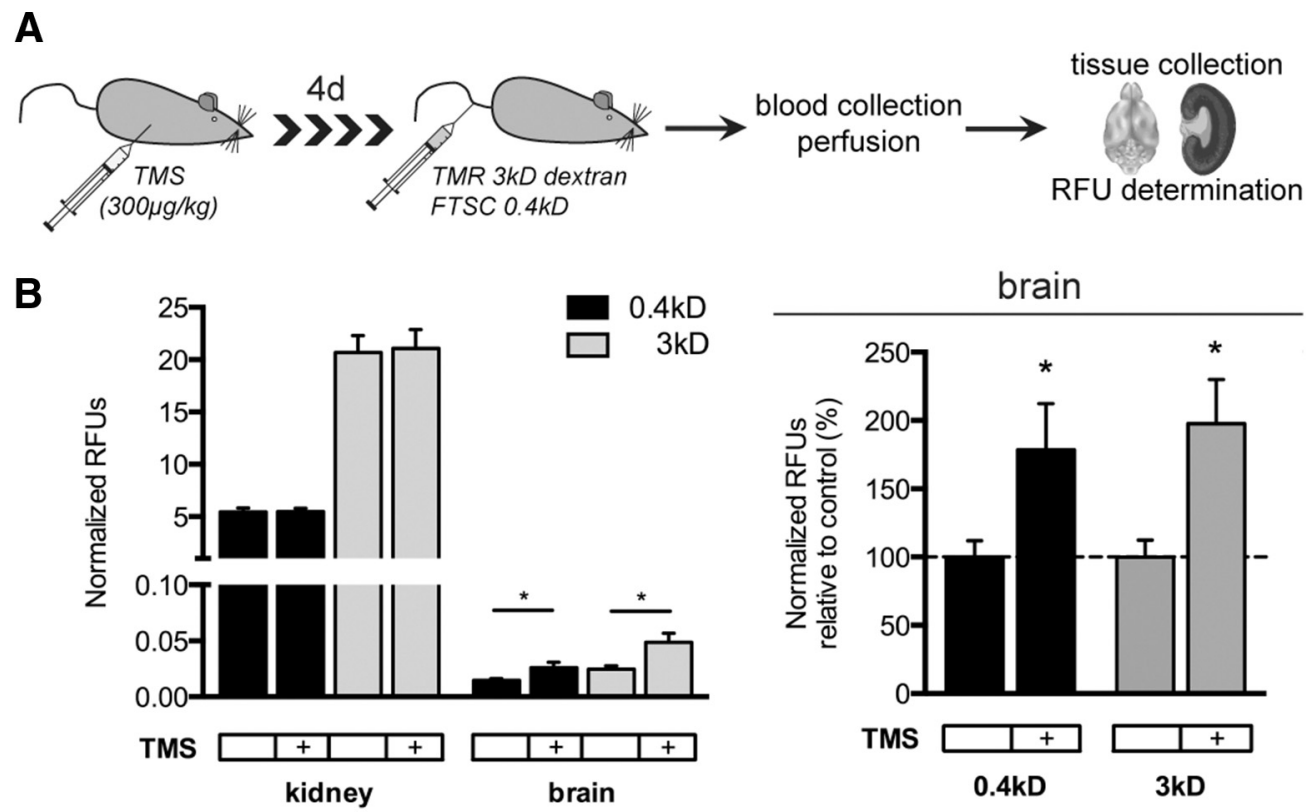

Figure 10. Cyp1b1 inhibition in vivo increases brain vessel permeability. $\boldsymbol{A}$, Schematic description of Cyp1b1 inhibition in C57BL/6JRJ WT mice followed by tracer experiment. $\boldsymbol{B}$, In vivo tracer experiment representing RFUs normalized to serum levels of kidney and brain homogenates for 0.4 kDa FTSC and TMR 3 kDa dextran (left). Normalized RFUs of brain homogenates of TMS-treated animals are shown as percentage relative to control animals (dashed line, right). 
A

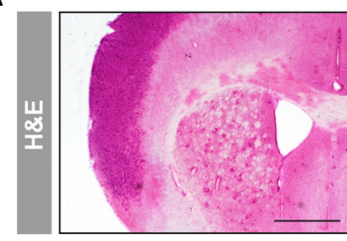

B

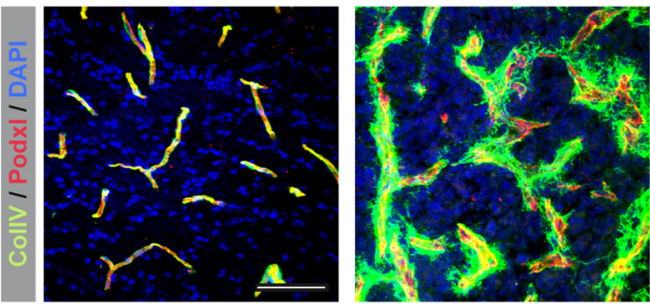

tumor

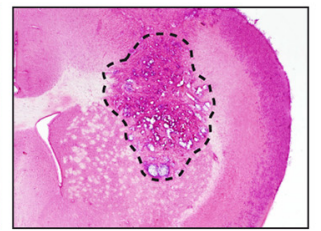

C

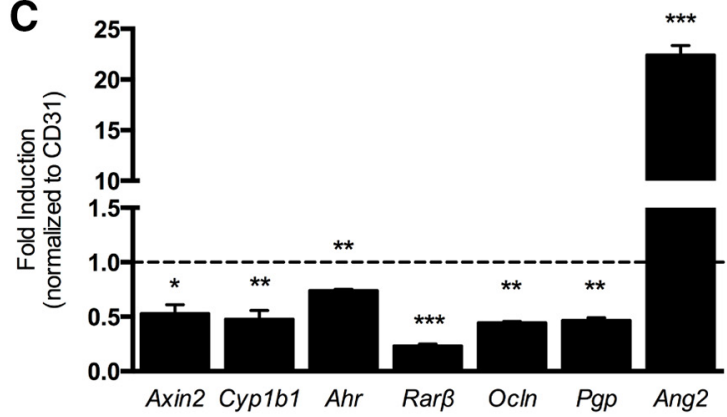

Figure 11. Cyp1b1 expression is downregulated in glioma vessels, going along with decreased RA target gene expression. $\boldsymbol{A}$, Representative pictures of $\mathrm{H} \& \mathrm{E}$ staining of control brain hemisphere (left) and tumor-bearing hemisphere (right) of mouse brains after intracranial tumor transplantation. Scale bar, $1 \mathrm{~mm}$. $\boldsymbol{B}$, Corresponding IF staining for CollV and Podxl. Scale bar, $100 \mu$ m. $\boldsymbol{C}$, qRT-PCR analysis for Axin2, Cyp 1b1, Ahr, as well as RA target genes and Ang2 in the tumor endothelium compared with ECs from the contralateral hemisphere (dashed line). Data represent means of three independent experiments. ${ }^{*} p<0.05 .{ }^{* *} p<0.01$. ${ }^{* * *} p<0.001$. Error bars indicate SEM.

tive cues if $\beta$-catenin was absent. Moreover, induction of $C y p 1 a 1$ by TCDD could be abrogated by inhibiting Ahr (Fig. $5 B$ ), suggesting that in ECs Cypla1 is exclusively regulated by Ahr and does not require $\beta$-catenin.

The profound upregulation of $C y p 1 b 1$ and concomitant suppression of Ahr and Cyplal in Cdh5 ${ }^{-1-}$ ECs (Fig. 3E-H) supports the mutually exclusive expression of the two CYPs and further suggests that Cyplb1 is strictly $\beta$-catenin-dependent. Along this line, analysis of epigenetic regulation of $C y p 1 b 1$ revealed a downregulation of active marks and upregulation of repressive marks in $\beta$-catenin $\mathrm{KO}$ ECs (Fig. $2 C, D$ ). For Cyp1a1, the opposite regulatory scheme was observed, suggesting that the mRNA expression is mirrored by promoter histone modification. However, further investigation is required to unravel the promotor regulation of endothelial CYP enzymes. Concerning the contribution of the noncanonical Wnt pathways to the regulation of $C y p 1 b 1$, our results point to a minor role of noncanonical signaling, which might be due to the inhibition of the canonical Wnt/ $\beta$-catenin pathway. This has been described for Wnt5a that can inhibit the canonical pathway (Yuan et al., 2011; Bisson et al., 2015). In line with this, downregulation of Cyp $1 b 1$ upon Wnt5a treatment in pMBMECs (Fig. 4A) supports that noncanonical Wnt signaling might indirectly modulate endothelial barrier properties, also by controlling endothelial polarity (Artus et al., 2014). Inhibition of the noncanonical pathways, however, did not result in significant regulation of Cyp $1 b 1$ in WT ECs (Fig. 4C). Interestingly, Cypla1 showed an upregulation upon calcineurin/NFAT inhibition by CsA and a downregulation upon JNK inhibition by SP600125, nicely correlating with the opposed regulation of these pathways in $\beta$-catenin KOs (Fig. 4B). These findings again support the conclusion that $C y p 1 b 1$ regulation in ECs is strictly $\beta$-catenin-dependent, whereas Cyplal might be regulated through Ahr and noncanonical pathways.

To understand Cyp1b1 function in ECs, we first concentrated on its angiogenic activity, as Cyp1b1-deficient ECs mice fail to form vascular cords on Matrigel (Tang et al., 2009). Similarly, $\beta$-catenin KO ECs largely lack cord formation in vitro (Cattelino et al., 2003). We hypothesized that the angiogenic phenotype of $\beta$-catenin-deficient embryos is partially due to downregulated Cyp1b1. However, rescue of Cyp1b1 expression in $\beta$-catenin $\mathrm{KO}$ ECs could not revert the cord-forming deficiency (Fig. 6). In- stead, reexpression of $\beta$-catenin in $\beta$-catenin KO ECs rescued cord formation, suggesting that $\beta$-catenin is required for angiogenesis independently from Cyp $1 b 1$.

Because of its strong expression in CNS vessels, the function of Cyp1b1 in metabolizing RA from RO could be of importance given the emerging role of RA in $\mathrm{BBB}$ formation (Chambers et al., 2007; Mizee et al., 2013; Lippmann et al., 2014). Specifically, it has been shown that astrocyte-derived RA upregulates BBB-relevant genes, such as VE-cadherin, Ocln, ZO-1, and Pgp in ECs. Interestingly, we observed reduced RA generation in $\beta$-catenin $\mathrm{KO}$ ECs, resulting in a lack of Pgp upregulation upon RO treatment, whereas the product RA upregulated Pgp in $\beta$-catenin KOs, but not Ocln as reported by Mizee et al. (2013). This observation supports the common belief that the formation of tight junctions is dependent on the presence of functional adherens junctions (Tietz and Engelhardt, 2015). Furthermore, our results provide evidence that the endothelium itself contributes to the generation of RA by Cyp 1 b1 that could take place in a RALDH-independent manner (Chambers et al., 2007). In the developing brain, radial glia have been shown to release large amounts of RA, likely acting on RA receptor $\beta$-positive ECs. During development the endothelial autonomous generation of RA might not be required, but in the adult EC-derived RA could contribute to barrier maintenance when astrocytic RA release has ceased. This interpretation fits well to recent findings demonstrating a low-level $\mathrm{Wnt} / \beta$ catenin signaling activity in brain ECs, which is crucial for maintaining barrier properties in the adult (Zhou et al., 2014).

In the context of BBB maintenance and endothelial homeostasis, Cyp1b1 might have functions beyond the metabolization of RO. This is supported by the results of screening $\beta$-catenin WT, KO, and KO ECs reexpressing Cyp $1 \mathrm{~b} 1$ for lipid metabolites, showing that specifically 20 -HETE was significantly downregulated in $\beta$-catenin $\mathrm{KO}$ ECs that was rescued by reexpressing Cyp1b1 (Fig. 8A). Interestingly, 20-HETE could be shown to regulate vascular tone (Pratt et al., 1998; Mulligan and MacVicar, 2004; Jacobs, 2006) and EC proliferation by increasing VEGF (Chen et al., 2014). Although conflicting data exist on whether the vascular endothelium is capable of generating 20-HETE (Wu et al., 2014), our data indeed support this possibility. With regard to its potential function at the $\mathrm{BBB}$, our data suggest that 20HETE modulates barrier properties evidenced by decreased 


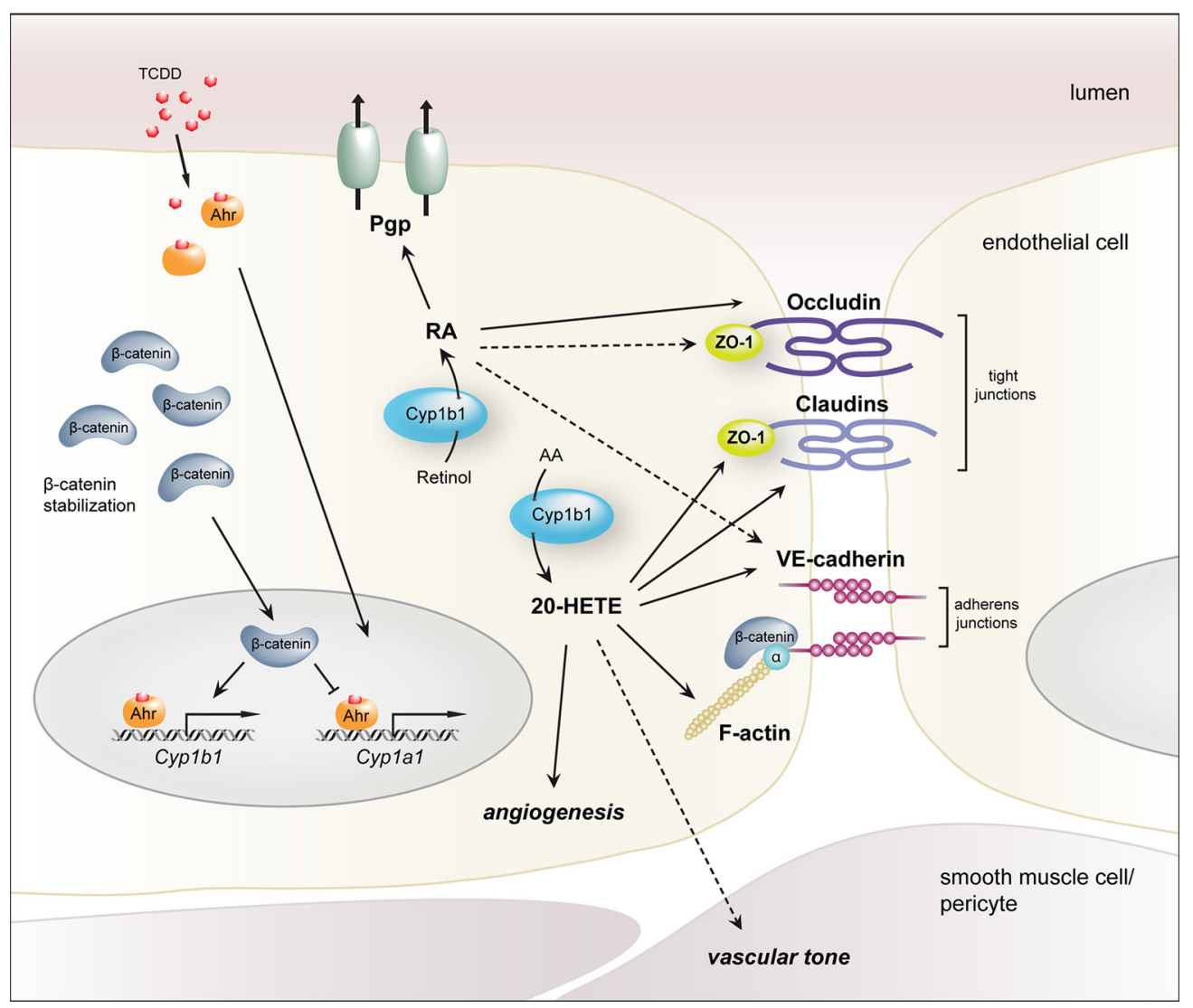

Figure 12. Proposed model of Cyp1a1 and Cyp 1b1 transcriptional activity as well as Cyp1b1 function in ECs. Cyp1b1 transcriptional activation in ECs is dependent on the availability of $\beta$-catenin, which upon stabilization acts as a transcriptional activator. Cyp1a1 transcription, in contrast, is not dependent on the presence of $\beta$-catenin. The cell-autonomous, Cyp1b1-mediated metabolism of RA from retinol improves endothelial barrier properties by augmenting the tight and adherens junction proteins $0 \mathrm{cln}, \mathrm{ZO}-1$, and VE-cadherin as well as by increasing Pgp function. Synthesis of the AA-metabolite 20-HETE also alters junction protein expression by downregulating Z0-1 and CIdn5, but upregulating VE-cadherin and concomitantly, increasing permeability. Additionally, 20-HETE influences cell morphology as well as physiological parameters as, for example, vascular tone and angiogenic processes. Under pathological conditions, such as glioma, Cyp $1 \mathrm{~b} 1$ becomes decreased in ECs, resulting in metabolic changes and, concomitantly, downstream effects on, for example, junction protein expression. Dashed arrows indicate relevant correlations, which are already described in the literature, but were not approached in the present study.

TEER, increased permeability, and reduced junctional localization of ZO-1 and Cldn5 (Fig. 8B-E). Surprisingly, the expression of VE-cadherin was enhanced in a dose-dependent manner in a mouse brain endothelioma cell line (Fig. 9A). This does not necessarily stand in contradiction to a barrier-opening effect as VEcadherin has been shown to be downregulated in the mature BBB compared with peripheral vessels (Breier et al., 1996). Our data suggest that Cyp1b1 via production of 20-HETE at the BBB may contribute to vascular function as well as to the angiogenic response of ECs. How the Cyp1b1 enzymatic function is regulated to either generate RA or 20-HETE remains to be elucidated. The increase in brain vessel permeability upon systemic inhibition of Cyp1b1 by TMS in mice in vivo suggests that, under steady-state conditions, the balance of Cyp1b1 products favors RA, resulting in a barrier promoting effect. If and how Cyplb1 function at the BBB may change under pathological conditions, such as atherosclerosis as well as in brain tumor and stroke, remains to be elucidated in more detail. However, we show that, in an experimental mouse glioma model, Cyp $1 b 1$ was downregulated along with the barrier-related target genes of the Wnt/ $\beta$-catenin and RA pathway Axin2, Ocln, and Pgp (Fig. 11), supporting the interpretation of $C y p 1 b 1$ being a BBB marker gene. Furthermore, the decrease of $C y p 1 b 1$ in glioma vessels and consequently the diminished endothelial RA signaling could lead to downregulation of the RA targets Ocln and Pgp, contributing to the overall tumor vessel characteristic and ultimately to disease progression.
In conclusion we provide first evidence that endothelial Wnt/ $\beta$-catenin signaling is indispensable for the transcriptional regulation of Cyp1b1 but not for Cyp1a1, which only depends on Ahr and possibly on noncanonical Wnt pathway activation. Cyp $1 b 1$ and Cyplal expression in ECs is mutually exclusive and seems to be regulated on the promoter level. We further show that the high expression levels of Cyp1b1 in ECs of the CNS may regulate endothelial production of RA as well as 20-HETE, thereby contributing to BBB maintenance and vascular homeostasis in vivo and in vitro (Fig. 12). The present findings underline the central role of $\beta$-catenin transcription for the establishment and maintenance of the complex BBB phenotype in ECs, affecting also metabolic pathways, such as the cytochrome P450 system and specifically Cyp $1 b 1$.

\section{References}

Agoston Z, Heine P, Brill MS, Grebbin BM, Hau AC, Kallenborn-Gerhardt W, Schramm J, Götz M, Schulte D (2014) Meis2 is a Pax6 co-factor in neurogenesis and dopaminergic periglomerular fate specification in the adult olfactory bulb. Development 141:28-38. CrossRef Medline

Artus C, Glacial F, Ganeshamoorthy K, Ziegler N, Godet M, Guilbert T, Liebner S, Couraud PO (2014) The Wnt/planar cell polarity signaling pathway contributes to the integrity of tight junctions in brain endothelial cells. J Cereb Blood Flow Metab 34:433-440. CrossRef Medline

Ben-Zvi A, Lacoste B, Kur E, Andreone BJ, Mayshar Y, Yan H, Gu C (2014) Mfsd2a is critical for the formation and function of the blood-brain barrier. Nature 509:507-511. CrossRef Medline 
Bisson JA, Mills B, Paul Helt JC, Zwaka TP, Cohen ED (2015) Wnt5a and Wnt1 1 inhibit the canonical Wnt pathway and promote cardiac progenitor development via the Caspase-dependent degradation of AKT. Dev Biol 398:80-96. CrossRef Medline

Braeuning A, Köhle C, Buchmann A, Schwarz M (2011) Coordinate regulation of cytochrome P450 1A1 expression in mouse liver by the aryl hydrocarbon receptor and the $\beta$-catenin pathway. Toxicol Sci 122:16-25. CrossRef Medline

Breier G, Breviario F, Caveda L, Berthier R, Schnürch H, Gotsch U, Vestweber D, Risau W, Dejana E (1996) Molecular cloning and expression of murine vascular endothelial-cadherin in early stage development of cardiovascular system. Blood 87:630-641. Medline

Carmeliet P, Lampugnani MG, Moons L, Breviario F, Compernolle V, Bono F, Balconi G, Spagnuolo R, Oosthuyse B, Dewerchin M, Zanetti A, Angellilo A, Mattot V, Nuyens D, Lutgens E, Clotman F, de Ruiter MC, Gittenberger-de Groot A, Poelmann R, Lupu F, et al. (1999) Targeted deficiency or cytosolic truncation of the VE-cadherin gene in mice impairs VEGF-mediated endothelial survival and angiogenesis. Cell 98: 147-157. CrossRef Medline

Cattelino A, Liebner S, Gallini R, Zanetti A, Balconi G, Corsi A, Bianco P, Wolburg H, Moore R, Oreda B, Kemler R, Dejana E (2003) The conditional inactivation of the $\beta$-catenin gene in endothelial cells causes a defective vascular pattern and increased vascular fragility. J Cell Biol 162: 1111-1122. CrossRef Medline

Chambers D, Wilson L, Maden M, Lumsden A (2007) RALDHindependent generation of retinoic acid during vertebrate embryogenesis by CYP1B1. Development 134:1369-1383. CrossRef Medline

Chen H, Howald WN, Juchau MR (2000) Biosynthesis of all-trans-retinoic acid from all-trans-retinol: catalysis of all-trans-retinol oxidation by human P-450 cytochromes. Drug Metab Dispos 28:315-322. Medline

Chen L, Ackerman R, Saleh M, Gotlinger KH, Kessler M, Mendelowitz LG, Falck JR, Arbab AS, Scicli AG, Schwartzman ML, Yang J, Guo AM (2014) 20-HETE regulates the angiogenic functions of human endothelial progenitor cells and contributes to angiogenesis in vivo. J Pharmacol Exp Ther 348:442-451. CrossRef Medline

Conway DE, Sakurai Y, Weiss D, Vega JD, Taylor WR, Jo H, Eskin SG, Marcus CB, McIntire LV (2009) Expression of CYP1A1 and CYP1B1 in human endothelial cells: regulation by fluid shear stress. Cardiovasc Res 81: 669-677. CrossRef Medline

Daneman R, Agalliu D, Zhou L, Kuhnert F, Kuo CJ, Barres BA (2009) Wnt/ $\beta$-catenin signaling is required for CNS, but not non-CNS, angiogenesis. Proc Natl Acad Sci U S A 106:641-646. CrossRef Medline

Dauchy S, Dutheil F, Weaver RJ, Chassoux F, Daumas-Duport C, Couraud PO, Scherrmann JM, De Waziers I, Declèves X (2008) ABC transporters, cytochromes P450 and their main transcription factors: expression at the human blood-brain barrier. J Neurochem 107:1518-1528. CrossRef Medline

Dermietzel R, Krause D, Kremer M, Wang C, Stevenson B (1992) Pattern of glucose transporter (Glut 1) expression in embryonic brains is related to maturation of blood-brain barrier tightness. Dev Dyn 193:152-163. CrossRef Medline

Dutheil F, Jacob A, Dauchy S, Beaune P, Scherrmann JM, Declèves X, Loriot MA (2010) ABC transporters and cytochromes P450 in the human central nervous system: influence on brain pharmacokinetics and contribution to neurodegenerative disorders. Expert Opin Drug Metab Toxicol 6:1161-1174. CrossRef Medline

Eelen G, de Zeeuw P, Simons M, Carmeliet P (2015) Endothelial cell metabolism in normal and diseased vasculature. Circ Res 116:1231-1244. CrossRef Medline

Engelhardt B, Liebner S (2014) Novel insights into the development and maintenance of the blood-brain barrier. Cell Tissue Res 355:687-699. CrossRef Medline

Fleming I (2014) The pharmacology of the cytochrome P450 rpoxygenase/ soluble epoxide hydrolase axis in the vasculature and cardiovascular disease. Pharmacol Rev 66:1106-1140. CrossRef Medline

Fleming I, Fisslthaler B, Dixit M, Busse R (2005) Role of PECAM-1 in the shear-stress-induced activation of Akt and the endothelial nitric oxide synthase (eNOS) in endothelial cells. J Cell Sci 118:4103-4111. CrossRef Medline

Frömel T, Jungblut B, Hu J, Trouvain C, Barbosa-Sicard E, Popp R, Liebner S, Dimmeler S, Hammock BD, Fleming I (2012) Soluble epoxide hydrolase regulates hematopoietic progenitor cell function via generation of fatty acid diols. Proc Natl Acad Sci U S A 109:9995-10000. CrossRef Medline

Goodwin AM, Sullivan KM, D’Amore PA (2006) Cultured endothelial cells display endogenous activation of the canonical Wnt signaling pathway and express multiple ligands, receptors, and secreted modulators of Wnt signaling. Dev Dyn 235:3110-3120. CrossRef Medline

Jacobs ER (2006) VEGF-induced relaxation of pulmonary arteries is mediated by endothelial cytochrome P-450 hydroxylase. Am J Physiol Lung Cell Mol Physiol 291:L369-L377. CrossRef Medline

Lampugnani MG, Zanetti A, Breviario F, Balconi G, Orsenigo F, Corada M, Spagnuolo R, Betson M, Braga V, Dejana E (2002) VE-cadherin regulates endothelial actin activating Rac and increasing membrane association of Tiam. Mol Biol Cell 13:1175-1189. CrossRef Medline

Liebner S, Corada M, Bangsow T, Babbage J, Taddei A, Czupalla CJ, Reis M, Felici A, Wolburg H, Fruttiger M, Taketo MM, von Melchner H, Plate $\mathrm{KH}$, Gerhardt H, Dejana E (2008) Wnt/ $\beta$-catenin signaling controls development of the blood-brain barrier. J Cell Biol 183:409-417. CrossRef Medline

Lippmann ES, Al-Ahmad A, Azarin SM, Palecek SP, Shusta EV (2014) A retinoic acid-enhanced, multicellular human blood-brain barrier model derived from stem cell sources. Sci Rep 4:4160. CrossRef Medline

Michaelis UR, Fleming I (2006) From endothelium-derived hyperpolarizing factor (EDHF) to angiogenesis: epoxyeicosatrienoic acids (EETs) and cell signaling. Pharmacol Ther 111:584-595. CrossRef Medline

Mizee MR, Wooldrik D, Lakeman KA, van het Hof B, Drexhage JA, Geerts D, Bugiani M, Aronica E, Mebius RE, Prat A, de Vries HE, Reijerkerk A (2013) Retinoic acid induces blood-brain barrier development. J Neurosci 33:1660-1671. CrossRef Medline

Mizee MR, Nijland PG, van der Pol SM, Drexhage JA, van Het Hof B, Mebius R, van der Valk P, van Horssen J, Reijerkerk A, de Vries HE (2014) Astrocyte-derived retinoic acid: a novel regulator of blood-brain barrier function in multiple sclerosis. Acta Neuropathol 128:691-703. CrossRef Medline

Mulligan SJ, MacVicar BA (2004) Calcium transients in astrocyte endfeet cause cerebrovascular constrictions. Nature 431:195-199. CrossRef Medline

Nebert DW, Dalton TP (2006) The role of cytochrome P450 enzymes in endogenous signalling pathways and environmental carcinogenesis. Nat Rev Cancer 6:947-960. CrossRef Medline

Norvell SM, Alvarez M, Bidwell JP, Pavalko FM (2004) Fluid shear stress induces $\beta$-catenin signaling in osteoblasts. Calcif Tissue Int 75:396-404. CrossRef Medline

Paolinelli R, Corada M, Ferrarini L, Devraj K, Artus C, Czupalla CJ, Rudini N, Maddaluno L, Papa E, Engelhardt B, Couraud PO, Liebner S, Dejana E (2013) Wnt activation of immortalized brain endothelial cells as a tool for generating a standardized model of the blood brain barrier in vitro. PLoS One 8:e70233. CrossRef Medline

Pifferi F, Jouin M, Alessandri JM, Haedke U, Roux F, Perrière N, Denis I, Lavialle M, Guesnet P (2007) n-3 fatty acids modulate brain glucose transport in endothelial cells of the blood-brain barrier. Prostaglandins Leukot Essent Fatty Acids 77:279-286. CrossRef Medline

Pratt PF, Falck JR, Reddy KM, Kurian JB, Campbell WB (1998) 20-HETE relaxes bovine coronary arteries through the release of prostacyclin. Hypertension 31:237-241. CrossRef Medline

Procházková J, Kabátková M, Bryja V, Umannová L, Bernatík O, Kozubík A, Machala M, Vondrácek J (2011) The interplay of the aryl hydrocarbon receptor and $\beta$-catenin alters both AhR-dependent transcription and $\mathrm{Wnt} / \beta$-catenin signaling in liver progenitors. Toxicol Sci 122:349-360. CrossRef Medline

Reis M, Liebner S (2013) Wnt signaling in the vasculature. Exp Cell Res 319:1317-1323. CrossRef Medline

Reis M, Czupalla CJ, Ziegler N, Devraj K, Zinke J, Seidel S, Heck R, Thom S, Macas J, Bockamp E, Fruttiger M, Taketo MM, Dimmeler S, Plate KH, Liebner S (2012) Endothelial Wnt/ $\beta$-catenin signaling inhibits glioma angiogenesis and normalizes tumor blood vessels by inducing PDGF-B expression. J Exp Med 209:1611-1627. CrossRef Medline

Risau W, Wolburg H (1990) Development of the blood-brain barrier. Trends Neurosci 13:174-178. CrossRef Medline

Savas U, Jefcoate CR (1994) Dual regulation of cytochrome P450EF expression via the aryl hydrocarbon receptor and protein stabilization in $\mathrm{C} 3 \mathrm{H} /$ 10T1/2 cells. Mol Pharmacol 45:1153-1159. Medline

Schinkel AH, Smit JJ, van Tellingen O, Beijnen JH, Wagenaar E, van Deemter 
L, Mol CA, van der Valk MA, Robanus-Maandag EC, te Riele HP (1994) Disruption of the mouse mdrla P-glycoprotein gene leads to a deficiency in the blood-brain barrier and to increased sensitivity to drugs. Cell 77:491-502. CrossRef Medline

Stenman JM, Rajagopal J, Carroll TJ, Ishibashi M, McMahon J, McMahon AP (2008) Canonical Wnt signaling regulates organ-specific assembly and differentiation of CNS vasculature. Science 322:1247-1250. CrossRef Medline

Taddei A, Giampietro C, Conti A, Orsenigo F, Breviario F, Pirazzoli V, Potente M, Daly C, Dimmeler S, Dejana E (2008) Endothelial adherens junctions control tight junctions by VE-cadherin-mediated upregulation of claudin-5. Nat Cell Biol 10:923-934. CrossRef Medline

Tang Y, Scheef EA, Wang S, Sorenson CM, Marcus CB, Jefcoate CR, Sheibani $\mathrm{N}$ (2009) CYP1B1 expression promotes the proangiogenic phenotype of endothelium through decreased intracellular oxidative stress and thrombospondin-2 expression. Blood 113:744-754. CrossRef Medline

Tietz S, Engelhardt B (2015) Brain barriers: crosstalk between complex tight junctions and adherens junctions. J Cell Biol 209:493-506. CrossRef Medline

Tran KA, Zhang X, Predescu D, Huang X, Machado RF, Göthert JR, Malik AB, Valyi-Nagy T, Zhao YY (2016) Endothelial $\beta$-catenin signaling is required for maintaining adult blood-brain barrier integrity and CNS homeostasis. Circulation 133:177-186. CrossRef Medline
Tukey RH, Nebert DW (1984) Regulation of mouse cytochrome P3-450 by the Ah receptor: studies with a P3-450 cDNA clone. Biochemistry 23: 6003-6008. CrossRef Medline

Vleminckx K, Kemler R, Hecht A (1999) The C-terminal transactivation domain of beta-catenin is necessary and sufficient for signaling by the LEF-1/ $\beta$-catenin complex in Xenopus laevis. Mech Dev 81:65-74. CrossRef Medline

Walter W, Sánchez-Cabo F, Ricote M (2015) GOplot: an R package for visually combining expression data with functional analysis. Bioinformatics 31:2912-2914. CrossRef Medline

Wu CC, Gupta T, Garcia V, Ding Y, Schwartzman ML (2014) 20-HETE and blood pressure regulation. Cardiol Rev 22:1-12. CrossRef Medline

Yuan Y, Niu CC, Deng G, Li ZQ, Pan J, Zhao C, Yang ZL, Si WK (2011) The Wnt5a/Ror2 noncanonical signaling pathway inhibits canonical Wnt signaling in K562 cells. Int J Mol Med 27:63-69. CrossRef Medline

Zhang L, Savas U, Alexander DL, Jefcoate CR (1998) Characterization of the mouse Cyp1B1 gene: identification of an enhancer region that directs aryl hydrocarbon receptor-mediated constitutive and induced expression. J Biol Chem 273:5174-5183. CrossRef Medline

Zhou Y, Wang Y, Tischfield M, Williams J, Smallwood PM, Rattner A, Taketo MM, Nathans J (2014) Canonical WNT signaling components in vascular development and barrier formation. J Clin Invest 124:3825-3846. CrossRef Medline 